\title{
Stigma, HIV Risk, and Access to HIV Prevention and Treatment Services Among Men Who have Sex with Men (MSM) in the United States: A Scoping Review
}

\author{
Riddhi A. Babel ${ }^{1}$ (D $\cdot$ Peng Wang ${ }^{1} \cdot$ Edward J. Alessi ${ }^{2} \cdot$ Henry F. Raymond ${ }^{1} \cdot$ Chongyi Wei $^{3}$ \\ Accepted: 12 April 2021 / Published online: 18 April 2021 \\ () The Author(s), under exclusive licence to Springer Science+Business Media, LLC, part of Springer Nature 2021
}

\begin{abstract}
In light of recent advances in HIV prevention and treatment, we reviewed the literature to understand how different types of stigma impact HIV risk; access to HIV prevention, care, and treatment services; and related health outcomes among men who have sex with men (MSM) in the US. We conducted a scoping literature review of observational and qualitative studies that examined stigma and HIV-related outcomes among MSM. Our search identified 5794 studies, of which 47 met the eligibility criteria and were included in the final analysis. The review suggests that stigma remains a formidable barrier to engaging in HIV prevention and treatment among both HIV-negative and HIV-positive MSM. Among the studies of HIVpositive MSM, internalized stigma was related to lower levels of treatment engagement. HIV-positive MSM in the Southern part of the US were also more likely to engage in risky sexual behavior. Perceived health care discrimination was negatively associated with PrEP awareness, particularly among HIV-negative Black MSM. Among young MSM of color, intersectional stigma compounded the social structural barriers to PrEP adherence. Findings indicate that stigma reduction interventions should be implemented in diverse MSM communities to address the disproportionate burden of HIV along with critical gap in the care continuum. Further research should examine how individual types of stigma, including intersectional stigma, affect viral suppression and PrEP uptake and adherence, especially among MSM of color.
\end{abstract}

Keywords Stigma $\cdot$ Discrimination $\cdot$ Intersectionality $\cdot$ HIV $\cdot$ MSM $\cdot$ Scoping review

\begin{tabular}{|c|c|}
\hline \multicolumn{2}{|c|}{ Abbreviations } \\
\hline MSM & Men who have sex with men \\
\hline PrEP & Pre-exposure prophylaxis \\
\hline TasP & Treatment as prevention \\
\hline HIV & Human immunodeficiency virus \\
\hline $\mathrm{CDC}$ & Centers for disease control and prevention \\
\hline
\end{tabular}

Riddhi A. Babel

babelriddhi@gmail.com

1 Department of Biostatistics \& Epidemiology, Rutgers School of Public Health, 683 Hoes Ln W, Piscataway, NJ 08854, USA

2 Rutgers School of Social Work, New Brunswick, NJ, USA

3 Department of Health Behavior, Society, and Policy, Rutgers School of Public Health, Piscataway, NJ, USA

\section{Introduction}

Stigma is a social-psychological construct that manifests in a process by which individuals relegated to a particular social category are subjected to prejudice, discrimination, and unfair treatment because of this category [1,2]. Stigma has been shown to relate to host of negative health outcomes $[1,2]$. Thus, different domains of stigma have been studied to enhance health-related research and develop interventions that specifically target these domains. Enacted stigma refers to the actual experience of prejudice and discrimination that occurs due to one's social category (e.g., being the victim of a hate crime because one is gay) [3]. Anticipated stigma is the fear or expectation of being rejected due to, for example, one's social category (e.g., sexual identity, gender identity, race/ethnicity, or HIV serostatus) [4]. Perceived stigma refers to one's perception about how others might feel about them because they are part of stigmatized group [5]. Internalized stigma is the internalization of negative societal attitudes related to one's stigmatized identity, typically resulting in diminished self-worth [6]. Marginalized groups such as 
men who have sex with men (MSM) often contend with these various forms of stigma. Further, because they may also possess more than one minority status (e.g., Black, gay man), they may also experience intersectional stigma [7, 8], which studies have begun to demonstrate negatively impact HIV-related outcomes among MSM [9].

Understanding the impacts of stigma on HIV risk, prevention, and care among MSM warrants immediate attention, as empirical studies continue to show that MSM are disproportionately affected by HIV, despite advances in prevention and treatment [10-12]. In fact, in 2018, 1.1 million people in the US were living with HIV, with MSM accounting for approximately $69 \%$ of all the diagnosed HIV infections [13]. The burden that is concentrated among this population has been attributed to a combination of psychosocial factors contributing to syndemics among MSM [14-18]. For example, syndemic factors such as child abuse, substance use, depression, traumatic stress, as well as various forms of stigma interact to increase the vulnerability of these individuals and confer excess risk to HIV infection [15, 16, 19]. One of the suggested mechanisms is through minority stress pathway $[20,21]$. In addition to concurrently acting as factors that amplifies the risks for $\mathrm{HIV}$, stigma or marginalization associated with sexual identity, exploration, and race has also been known to act in an additive way through this path [17, 22].

In the absence of a cure for HIV infection, HIV prevention methods and programs that use antiretroviral treatment (ART), also referred to as Treatment as Prevention (TasP) can control and prevent further spread of the virus to uninfected individuals [23]. However, efficacy and effectiveness of TasP can be greatly reduced in MSM who are often stigmatized due to concurrent discriminations acting in unison. Different types of stigma such as internalized stigma, HIV related stigma, stigma experienced in healthcare settings impacts prevention strategies and results in reduced accessibility and decreased quality of care [24, 25]. Thus, stigma may play a significant role in hampering HIV prevention efforts among the MSM population. It can discourage them from seeking information, prevent them from getting tested, seeking care or support, and hinder access to biomedical interventions such as TasP and PrEP [26]. This has resulted in significant challenges when conducing biobehavioral HIV surveillance studies as well as understanding of the social structural factors contributing to HIV risk. In order to strengthen efforts to characterize and to reduce stigma and discrimination and further improve health outcomes, an improved understanding of how stigma impacts HIV risk and access to prevention and care among MSM is needed. Studies have assessed stigma in different ways, some examine it by using a scale while others adopted a more qualitative or a mixed method approach $[20,27,28]$. This paper presents a critical scoping review by summarizing the largely fragmented literature on stigma among MSM in the
United States as it pertains to risk of HIV infection, access to prevention, care and treatment services, and other health outcomes. The review is guided by the following research questions:

(1) How did the studies conceptualize and measure individual types of stigma as well as intersectional stigma?

(2) How did different types of stigma affect HIV risks, in particular syndemic conditions?

(3) What types of stigma negatively impact prevention (e.g., PrEP) and care continuum outcomes?

Our objectives were to summarize research on the associations between stigma and these different measures of HIV cascade by systematically reviewing peer-reviewed literature. In line with the broad coverage of our topic, a scoping review was chosen as the most appropriate methodology to inform the way research has been conducted [29].

\section{Methods}

\section{Search Strategy}

Original peer-reviewed articles published in English language journals from early 1980's to October 2019 were obtained from systematic searches of five electronic bibliographic databases: PubMed, CINAHL, Psych Info, Scopus, and Web Science. The search was implemented in November 2019. The search query consisted of terms such as stigma, discrimination, stereotype, gay, HIV, AIDS, MSM or other associated terms (supplementary file), and this was tailored to the specific requirements of each database. Grey literature, commentaries, or other document types such as reports, and essays were excluded since they were not peer reviewed. All identified articles from the searches were transferred to a bibliographic management system software program (EndNote, Rayyan). Duplicates were excluded by automatic duplication removal process in EndNote's default one step auto-deduplication process. The articles were further checked and then removed manually if they had not already been identified by the reference manager software. This was carried out independently by two reviewers (RAB, PW).

\section{Eligibility Criteria}

In order to be included in this scoping review, original peerreviewed articles had to meet three inclusion criteria. First, the study had to be conducted in the United States among the adult MSM population. This criterion was not limited to behavior only; we have included gay and bisexual men in this review. Second, the study had to examine at least one type of stigma and discrimination and have at least one 
HIV-related outcomes as the dependent variable (e.g., risk of HIV acquisition, HIV medication or treatment adherence, suppression of viral load, linkage to care, and HIV prevention measures such as HIV testing and PrEP use). Third, only peer-reviewed articles written in English that presented original quantitative, qualitative, or mixed methods research were considered. Studies were excluded if any of the above criteria were missing.

\section{Data Charting and Synthesis}

Applying the eligibility criteria, the two independent reviewers screened and assessed the articles using a twostep process. In the first step, the reviewers selected the articles based on title and abstract and in the second step they screened the full text of the articles that had been included in the first step. In circumstances where the title/abstract was deemed to not provide sufficient information, the full article was retrieved and examined before a final decision was made. All conflicts and disagreements generated through the screening stages between the two reviewers were discussed until consensus was reached. Furthermore, when needed, a third opinion from the senior author (CY) was consulted to reach unanimity. After the articles were selected, the following data was recorded in a spreadsheet for data extraction and charting: author(s), year, city/region, study purpose, study design (e.g., quantitative, qualitative, or mixed methods), exposure, outcomes measured, and key findings. To ensure accuracy, the same reviewers abstracted the data. We did not perform an assessment of the quality of included studies in align with the methodology of scoping reviews.

\section{Results}

\section{Search Results}

The initial literature search resulted in a total of 5,794 citations from the five electronic databases (PubMed: 1356, CINAHL: 921, Psych Info: 1346, Scopus: 392, and Web Science: 1779). After removing the duplicates, a total of 2,482 records were potentially eligible and were hence screened for title and abstract. Subsequent to this, a full text assessment of 217 articles were performed. The full-text screening led to 47 eligible articles relevant to our scoping review that were included in the final data extraction and further analysis. Figure 1 shows the flow chart of articles examined for this scoping review.

The results begin with an overall summary of the studies included in the scoping review and then describe the findings related to different types of stigma and its measurements, as well as its association with syndemic conditions, PrEP use, and the HIV care continuum.

\section{Characteristics of Studies}

The majority of studies were quantitative $(n=30)[20,24$, $28,30-56]$ with the remaining being qualitative studies $(n=16)[25,57-71]$. There was only one study that applied a mixed method study design [27]. Five studies spanned the larger geographical area of the United States, thereby including the 50 states $[31,36,38,39,52]$. Most frequently, the studies were conducted in New York City $(\mathrm{n}=15)[27,32$, $33,37,40,43,47,49,51,54,59,63,66,68,70]$, followed by Chicago $(n=6)[35,37,48,57,58,69]$, Los Angeles $(n=6)$ $[25,30,34,37,51,61]$, Boston $(n=5)[20,37,46,51,56]$, and San Francisco $(n=4)[27,28,37,51]$. Twenty-seven of the quantitative investigations were cross-sectional surveys $[24,28,30,31,33-41,43-56]$, and the remaining three were longitudinal studies [20,32, 42]. Of the seventeen qualitative and mixed method studies [25, 27, 57-71], seven were conducted using focus group discussions [25, 61-64, 67, 68] and the remaining were either in-depth or semi-structured interviews [27, 57-60, 65, 66, 69-71]. Approximately, 85\% $(\mathrm{n}=40)$ of all included studies were published in 2010 or later $[20,24,25,28,30-43,45-54,56-62,64,65,67,70$, 71].

Fewer studies $(\mathrm{n}=14)$ [20, 27, 30-35, 57-60, 70, 71] were conducted among HIV-positive MSM as compared to HIV-negative MSM ( $\mathrm{n}=33)$ [24, 25, 28, 36-56, 61-69]. Only one quantitative [35] and three qualitative studies [58-60] focused exclusively on the effects of stigma among HIV-positive African American MSM. In contrast, one qualitative study [71] focused on HIV-negative Hispanic MSM, while three other studies were conducted on both Hispanic and Black MSM populations [30, 34, 70]. Furthermore, among HIV-negative Black MSM, five quantitative [43, 45, $48,49,51]$ and six qualitative [25, 61, 63, 67-69] studies were conducted, whereas one qualitative study [62] was among Hispanic MSM. Lastly, there was only one quantitative study [41] that included both Black and Hispanic MSM.

\section{Types of Stigma}

Both quantitative and qualitative studies of MSM living with HIV showed that internalized, perceived and experienced HIV stigma was associated with increased prevalence of HIV-transmission risk behaviors and poorer self-reported health [20, 27, 30-35, 57-60, 70, 71] (Table 1). Among HIV-negative MSM, the most frequently measured stigma was experienced stigma due to sexual or racial prejudice [37, $38,40,41,43,48,53,55,56]$. Internalized and perceived stigma were less frequently assessed [24, 36, 39, 51], as were structural and healthcare discrimination $[42,44,45$, 47]. These various forms of stigma and discrimination have been shown to be negatively associated with willingness and awareness to use PrEP and engage in HIV testing but 
Fig. 1 Scoping review flow diagram
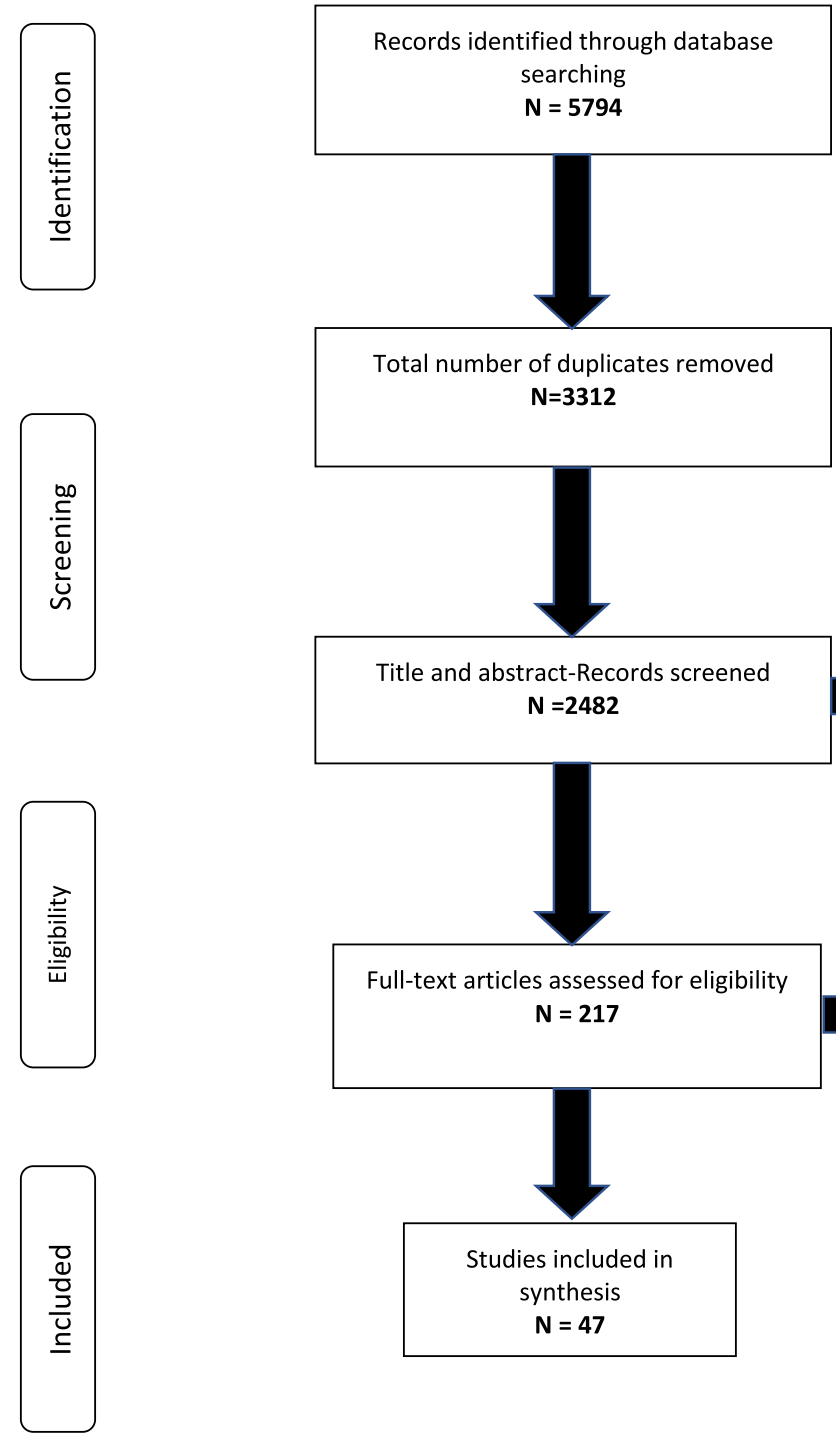

Total number of duplicates removed $\mathbf{N}=3312$
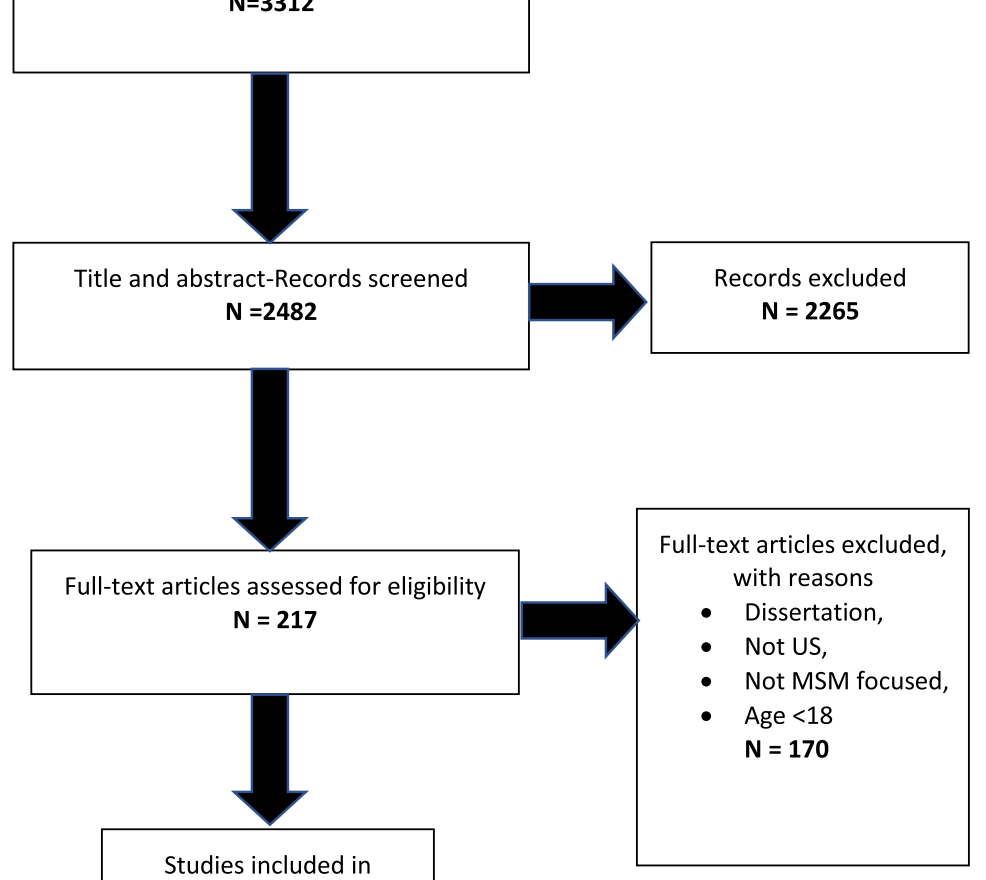

Studies included in synthesis $\mathbf{N}=47$ positively associated with engagement in high-risk sexual behavior [24, 25, 28, 36-56, 61-69] (Table 2).

\section{Intersectional Stigma}

Of all the studies reviewed, the theory of intersectionality was explicitly investigated in just one qualitative study [71]. Individual, community and structural determinants among MSM was informed by intersectional stigma in this particular study, which included Hispanic MSM living with HIV. This qualitative study assessed the salient intersections of identities among participants and how their multiple identities shaped HIV testing and treatment experiences. Findings from this study demonstrated that Hispanic MSM who are HIV-positive may find it easier to disclose their sexual orientation to family, friends, and sexual partners than their HIV status, due to both internalized and perceived HIV stigma [71]. Intersecting identities are even discriminated against within gay communities, leading to more social isolation and lesser support. Even though not explicitly investigating intersectional stigma, one of the significant findings of this particular study among HIV negative MSM is worth mentioning. It reported the interaction between enacted stigma and healthcare discrimination resulting in increased substance use and thus resulting in more risky behaviors such as condom less sex [56].

\section{Stigma and Syndemic Conditions}

Of the literature available on the interaction of syndemic conditions, six studies examined the relationships between stigma and syndemic conditions [20, 32, 35, 40, 46, 62]. The greater likelihood of sexual risk behavior among MSM can be explained by higher co-occurrence of psychosocial health problems, resulting in increased HIV infection. In a study of HIV negative Hispanic MSM, it was reported 


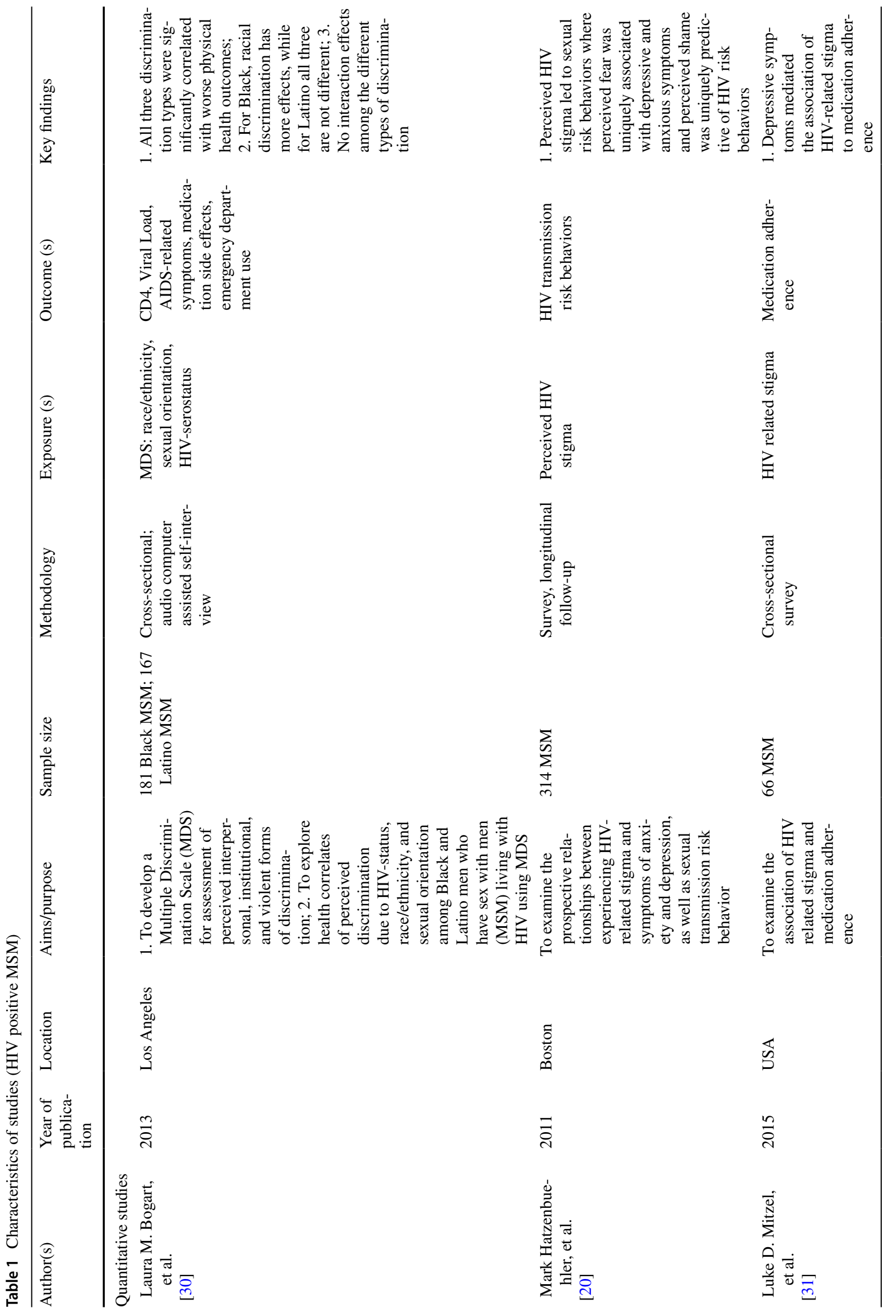




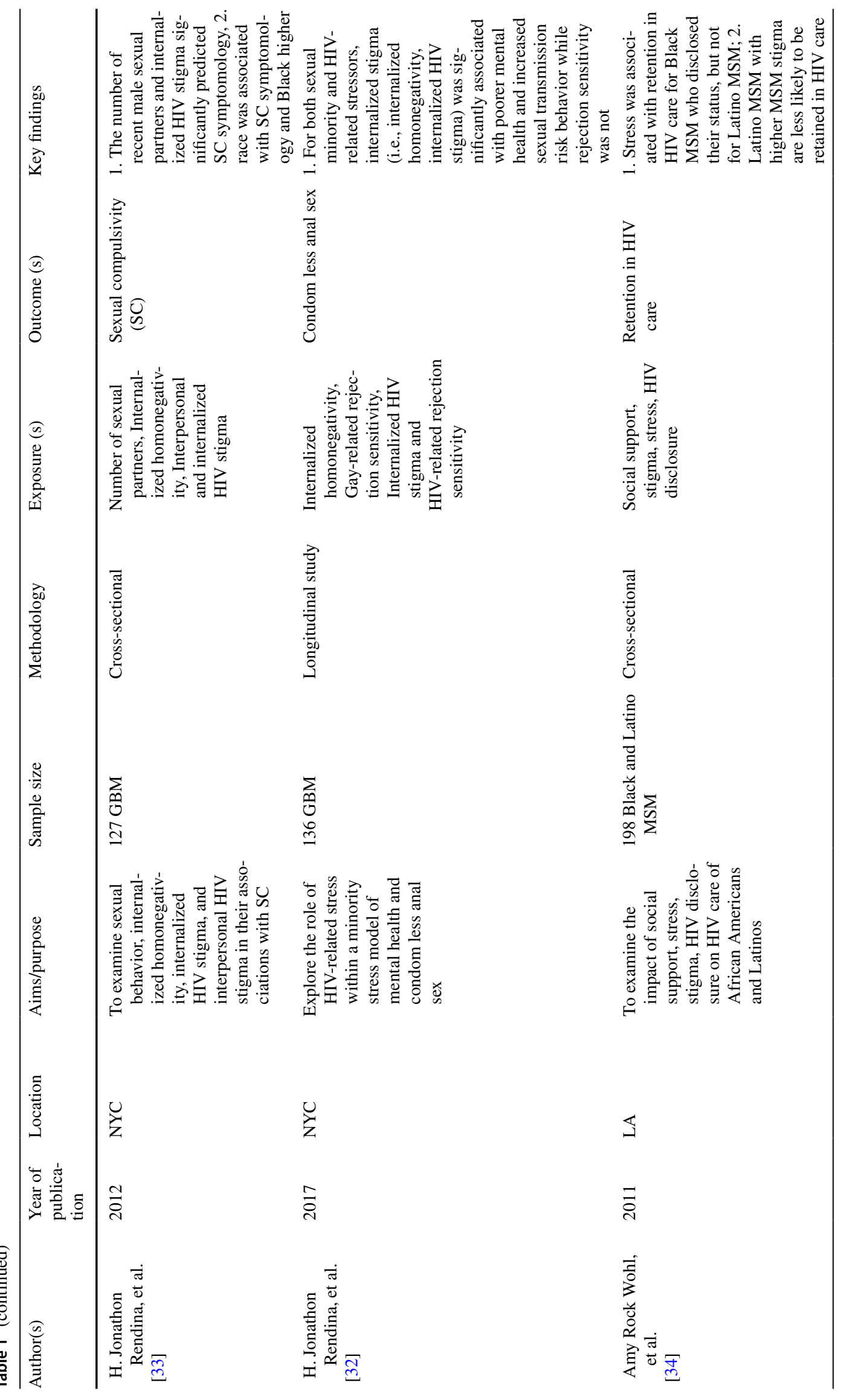




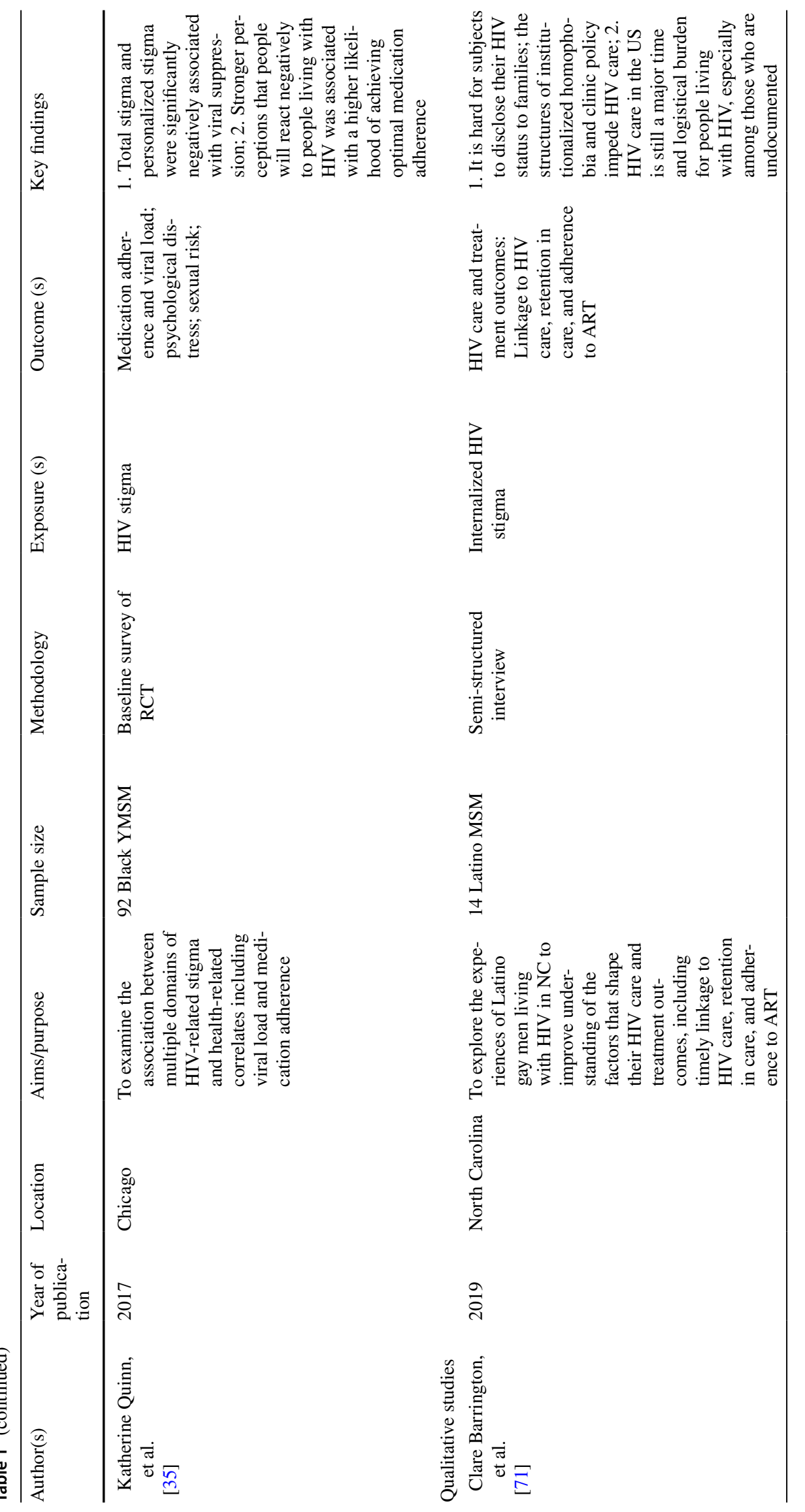




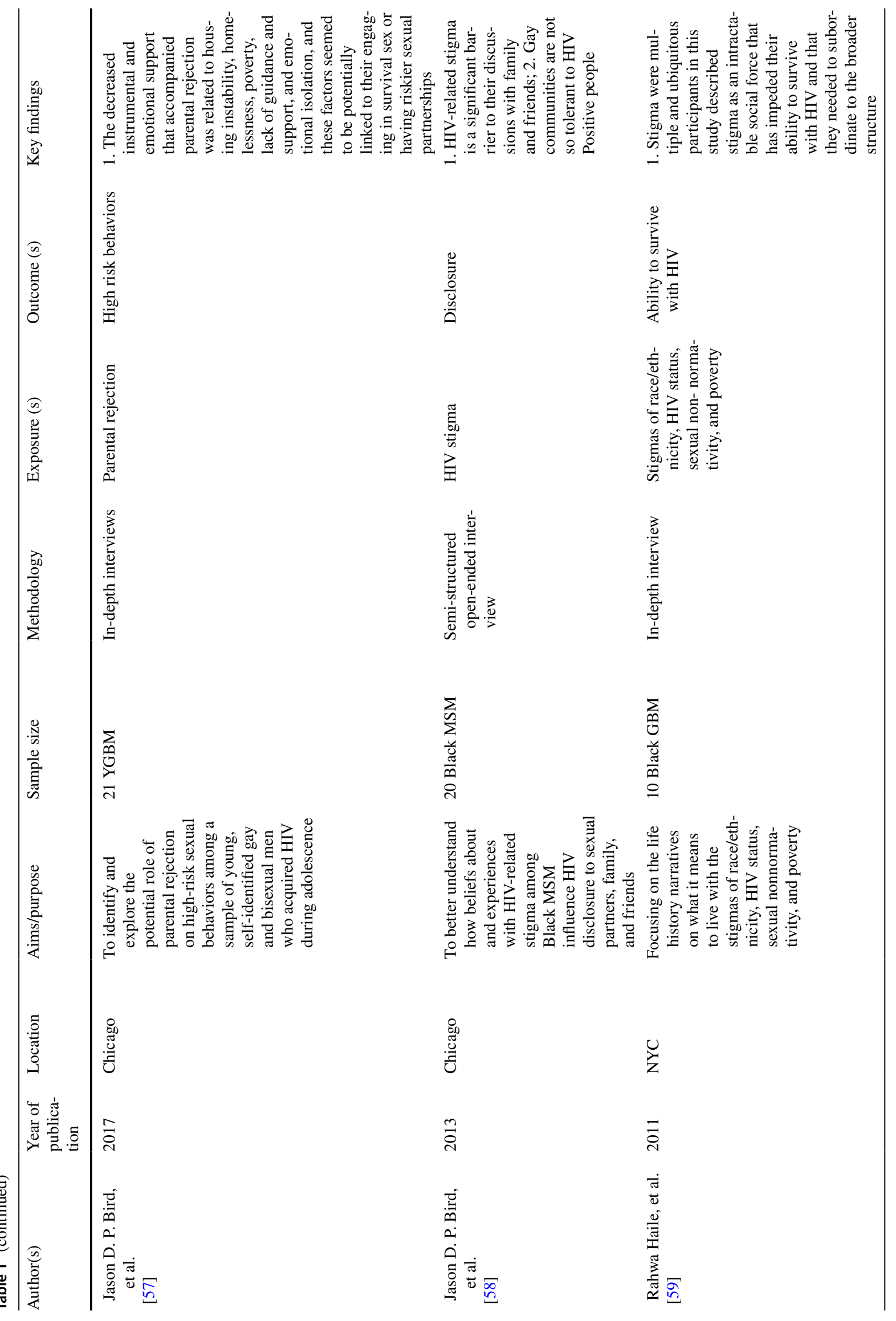




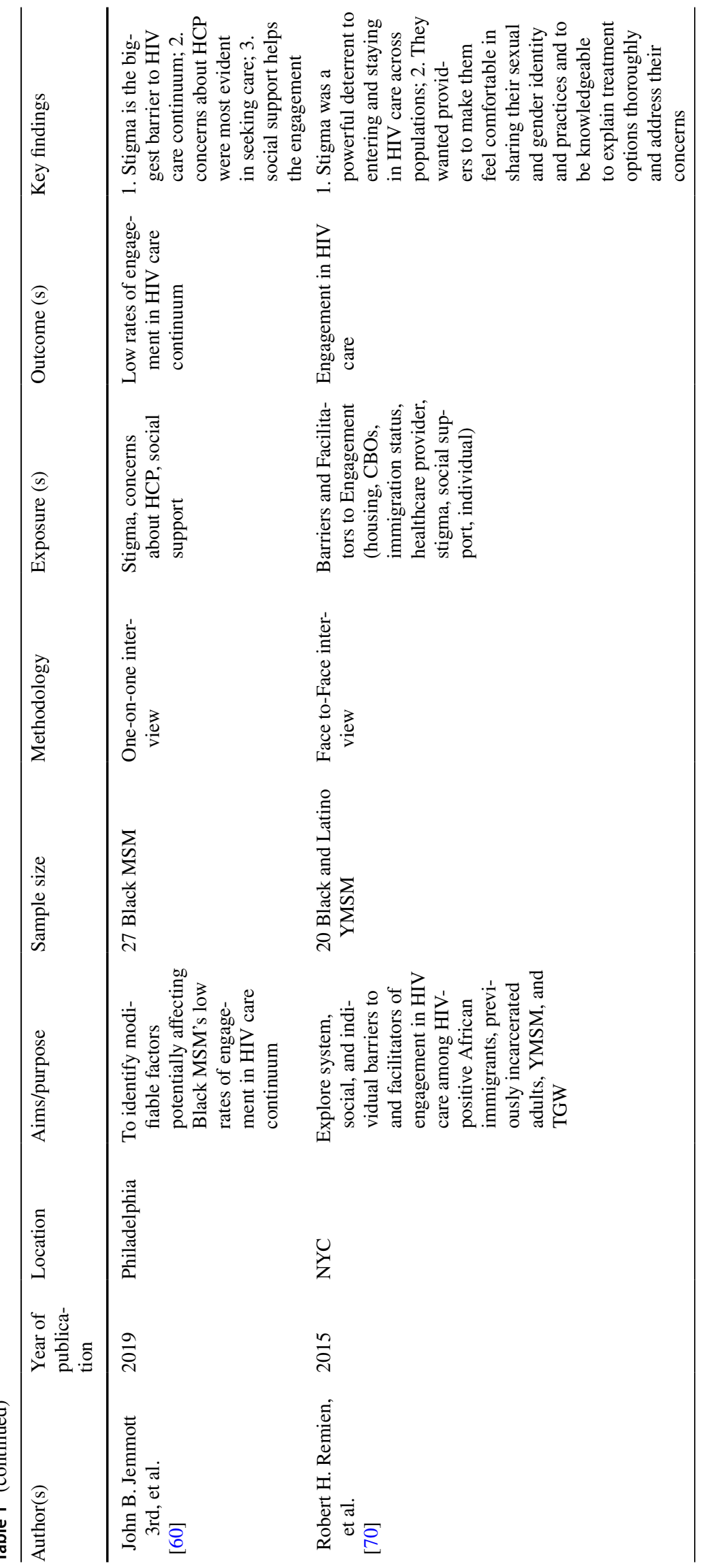




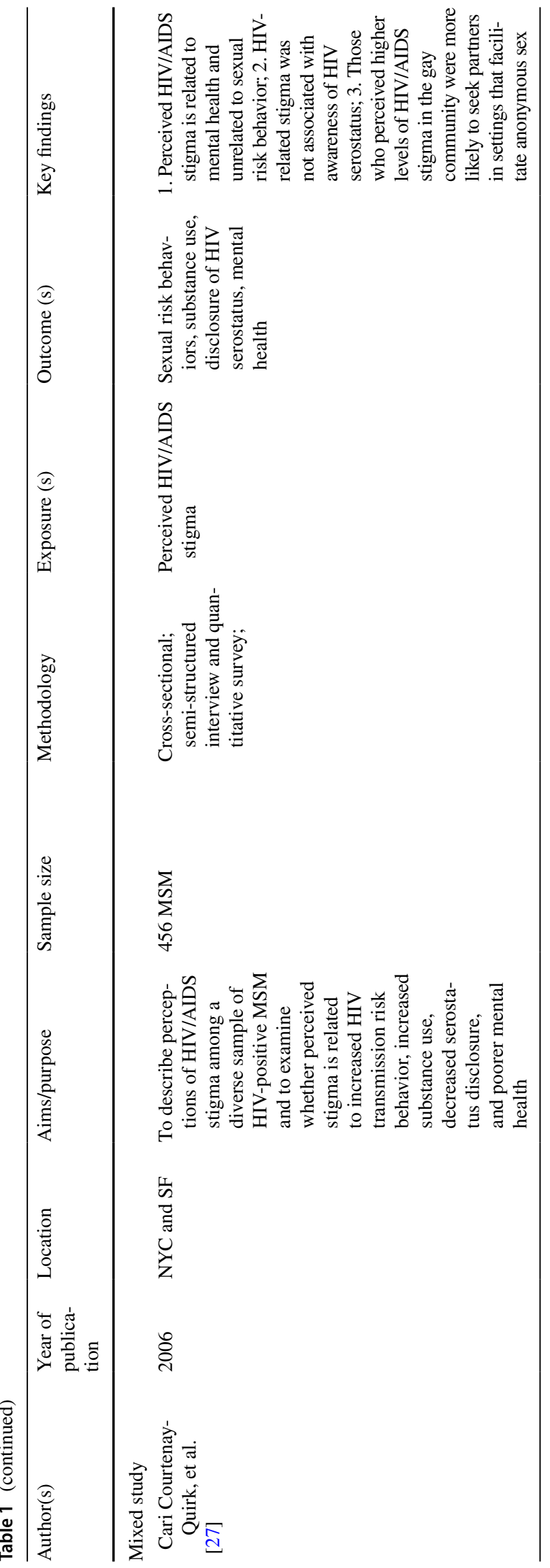

that various sexual behaviors and health and social conditions (sexual risk, substance abuse, and violence), which were compounded by heath disparities and social inequalities, increased their risk of HIV exposure [62]. This phenomenon is further intensified among African Americans, where co-occurring conditions like racism, HIV stigma, and substance use increase their risk of infection by acting as a barrier for PrEP adherence [46]. This was supplemented by another study, that reported substance abuse and mental health distress as consequences of sexual orientation-based discrimination, resulting in higher observed sexual risk [40]. Among HIV positive MSM, the stress associated with HIV stigma was one of the fundamental hypothesized and examined syndemic relationships that was considered to drive the HIV epidemic [20, 35]. This was strengthened by findings from a longitudinal study that reported that, internalized HIV stigma along with sexual minority stressor was significantly related with adverse mental health, which ultimately led to an increased risk of transmission [32].

\section{Stigma and PrEP, Care Continuum Outcomes}

Among HIV negative MSM, there were a total of 11 studies that assessed the association between stigma and PrEP awareness and use [24, 25, 45, 48, 50, 52, 61, 63-66]. In particular among Black and Hispanic MSM, perceived intolerance against someone with HIV resulted in the knowledge, awareness, and intention to take PrEP among them as being low. This was due to the cultural norms of belonging to a particular race, resulting in reduced visibility and availability of services $[24,50,65]$. In addition, among Black MSM, perceived health-care discrimination as result of race and sexual orientation led to negative awareness about PrEP, thereby, restricting information. However, disclosure of same-sex behavior to healthcare providers (HCP) was positively related to PrEP awareness [45]. Among trans-MSM, although knowledge about PrEP was high, its use was nevertheless low, due to internalized stigma as a result of sexual orientation [52]. Moreover, merely being cognizant about PrEP is not sufficient, its usage is increased if you know other PrEP users or individuals with recent infections in your network, thereby, bridging the gap between them [48]. Besides, major barriers have been noted pertaining to this high-risk population. As compared to young MSM (YMSM, ages 18-29), the awareness about PrEP was lower in older MSM [45]. In YMSM, the perception of HIV related stigma was identified as a formidable barrier to HIV testing [64]. In addition to this, among YMSM of color, other factors that contributed to not getting tested was unfriendly environment at the testing centers attributable to one's race and lack of support within community [25, 63]. Moreover, lack of knowledge among both MSM and some HCP as they are not comfortable in prescribing PrEP, low awareness about 


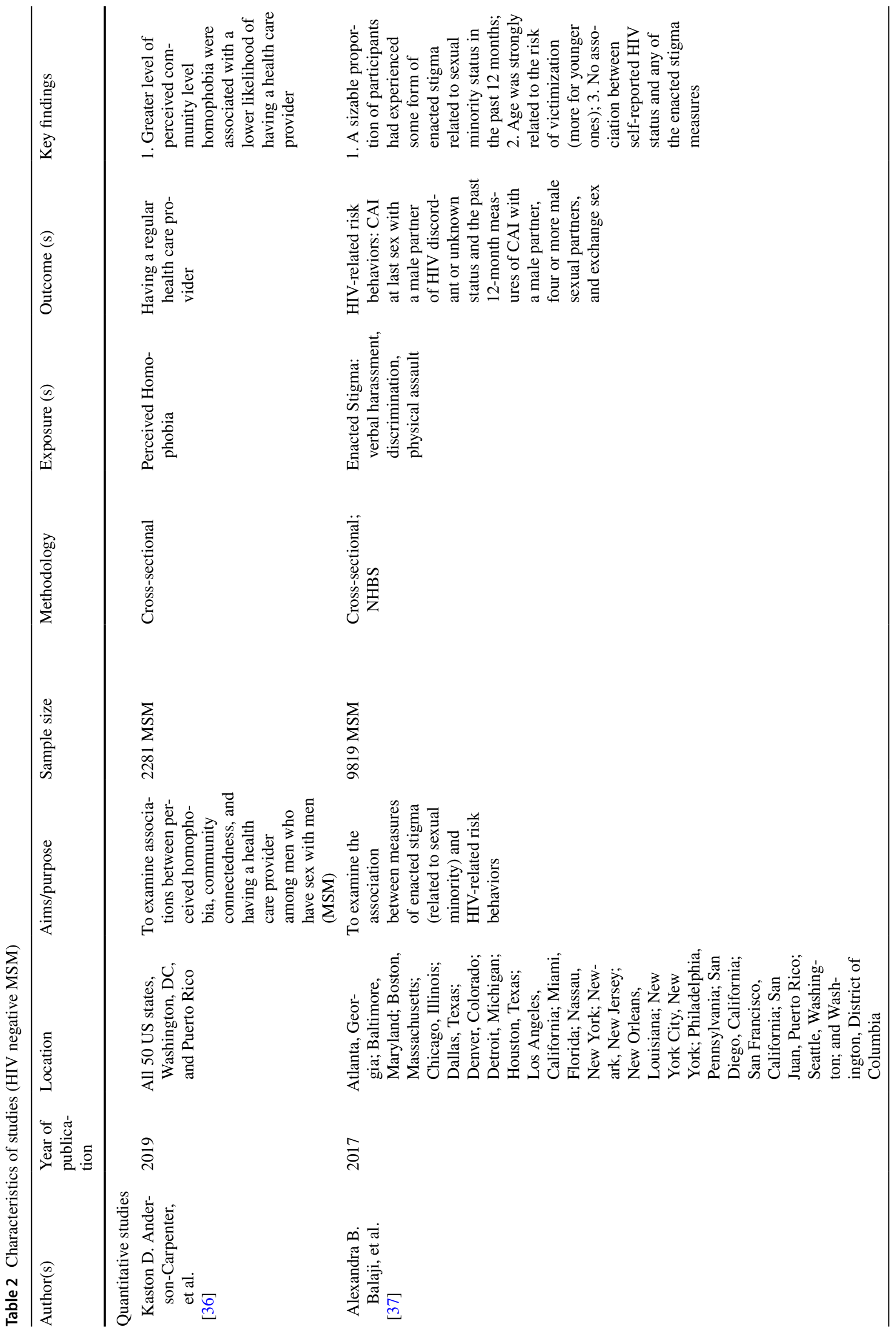




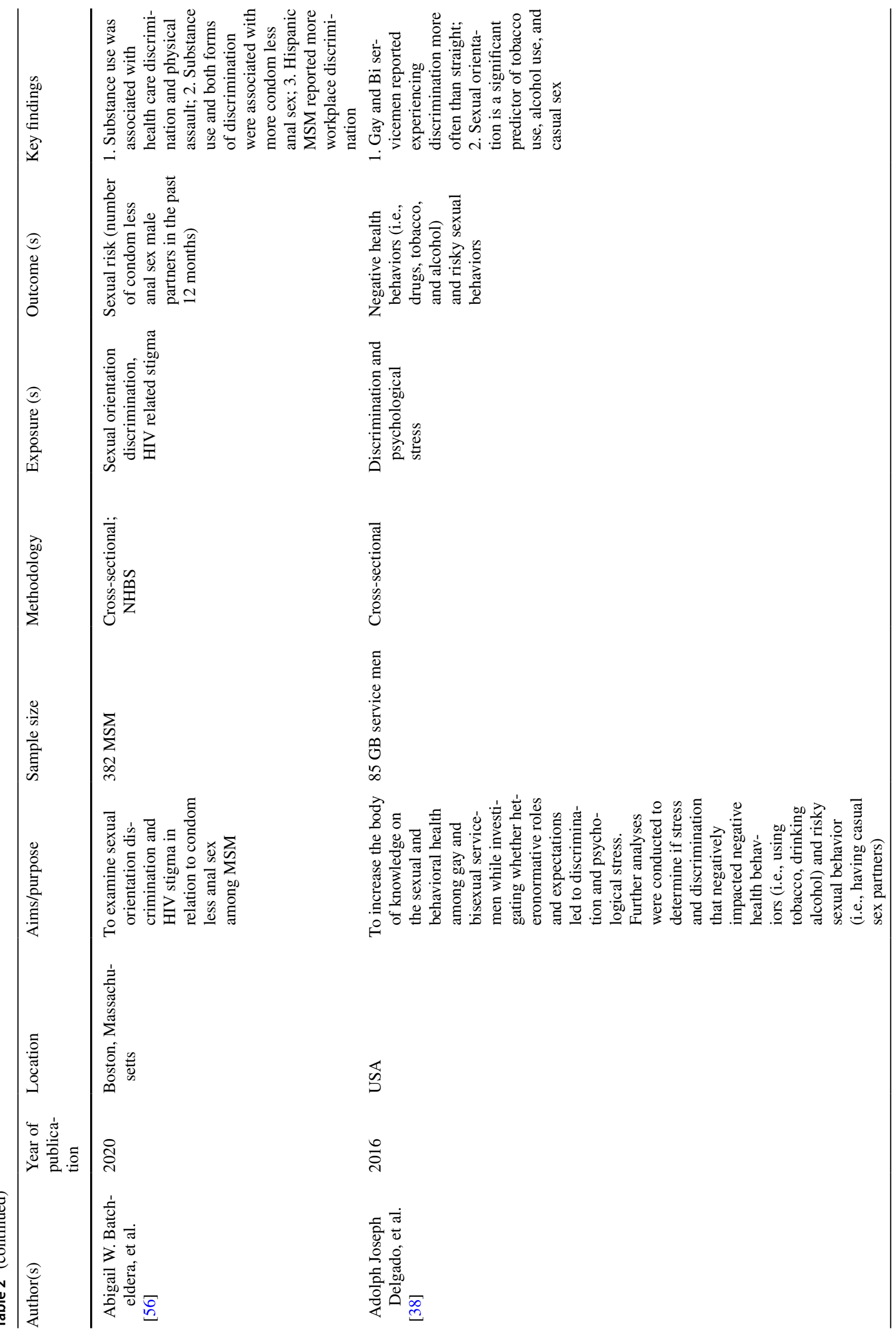




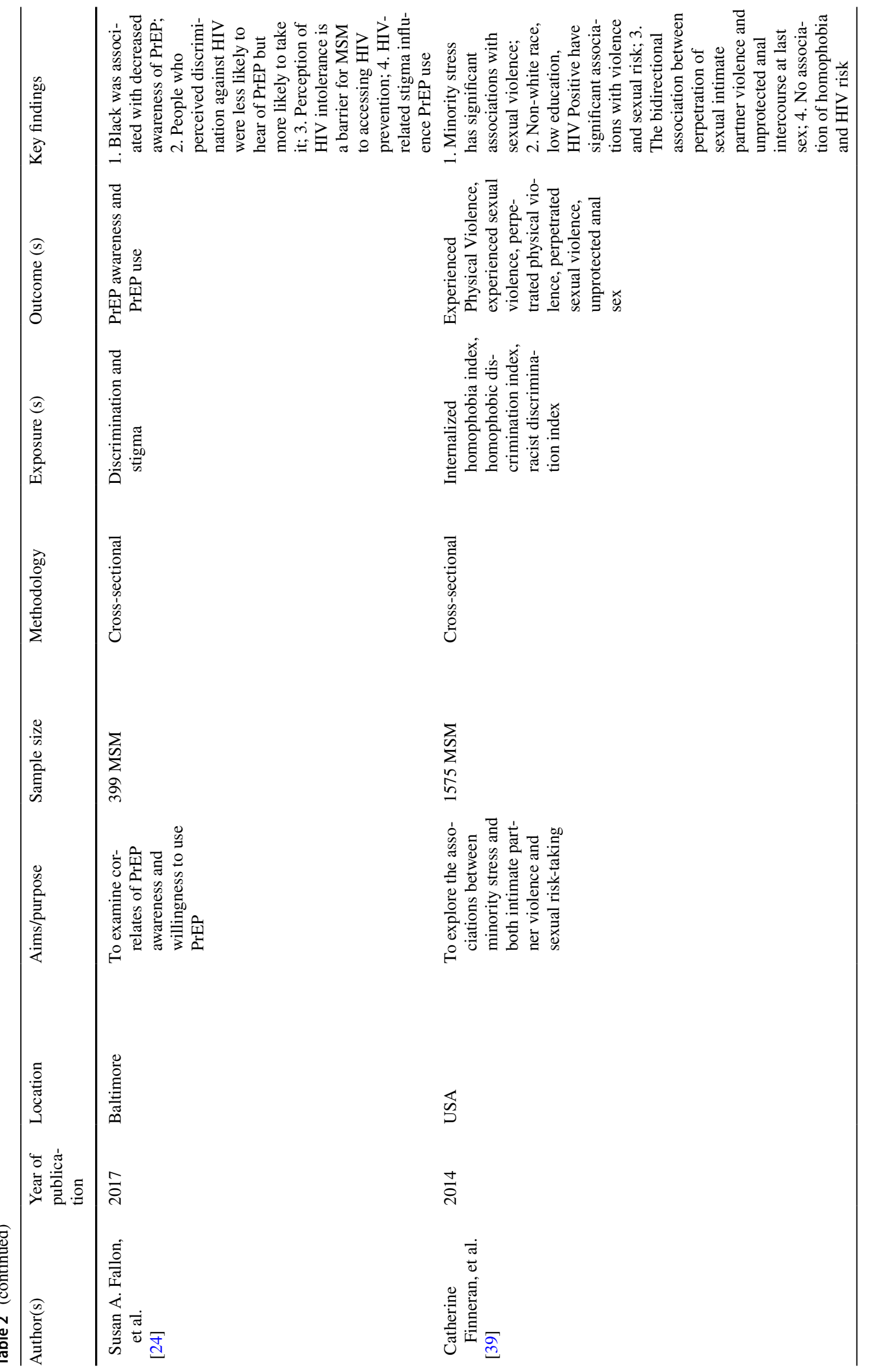




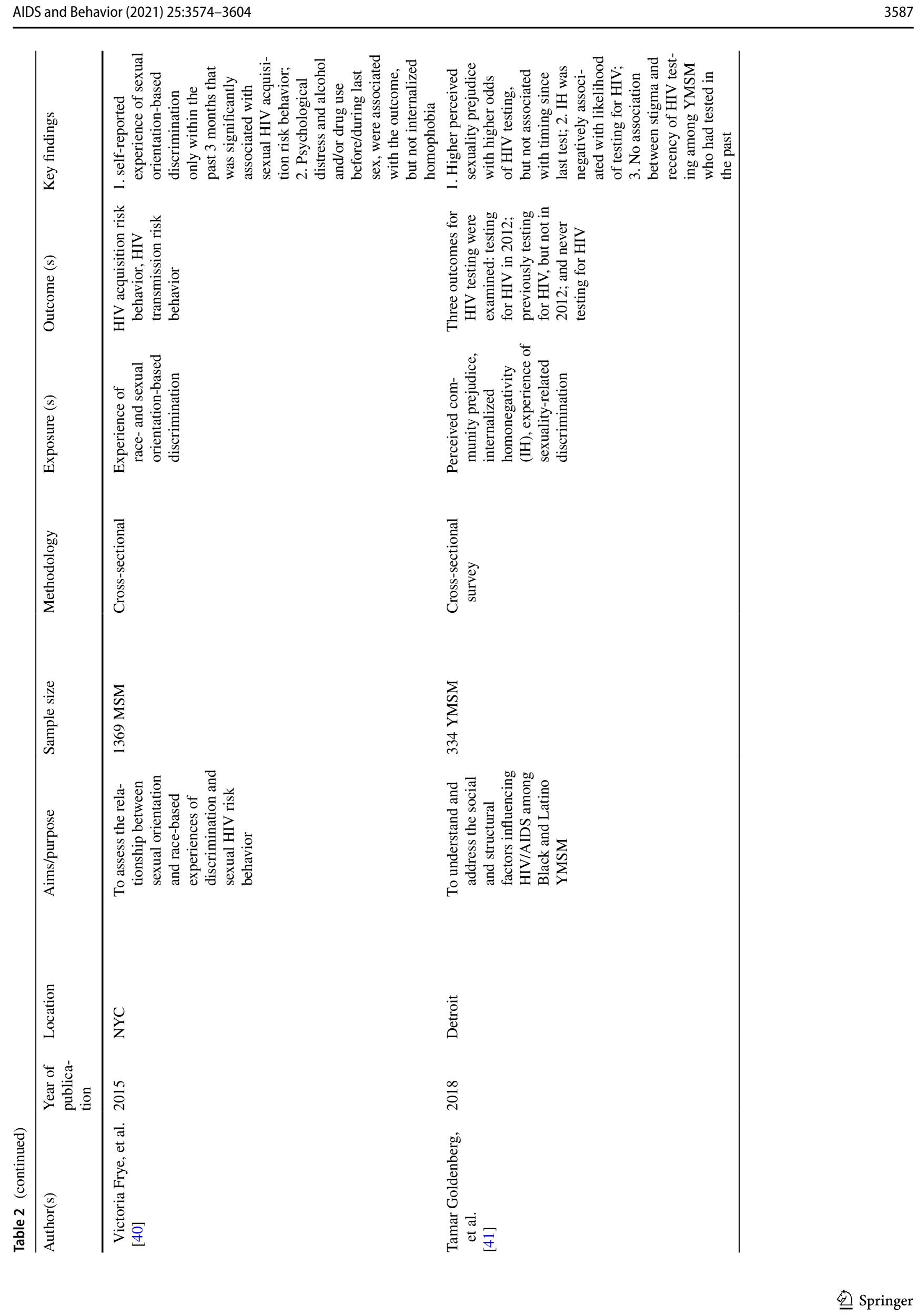




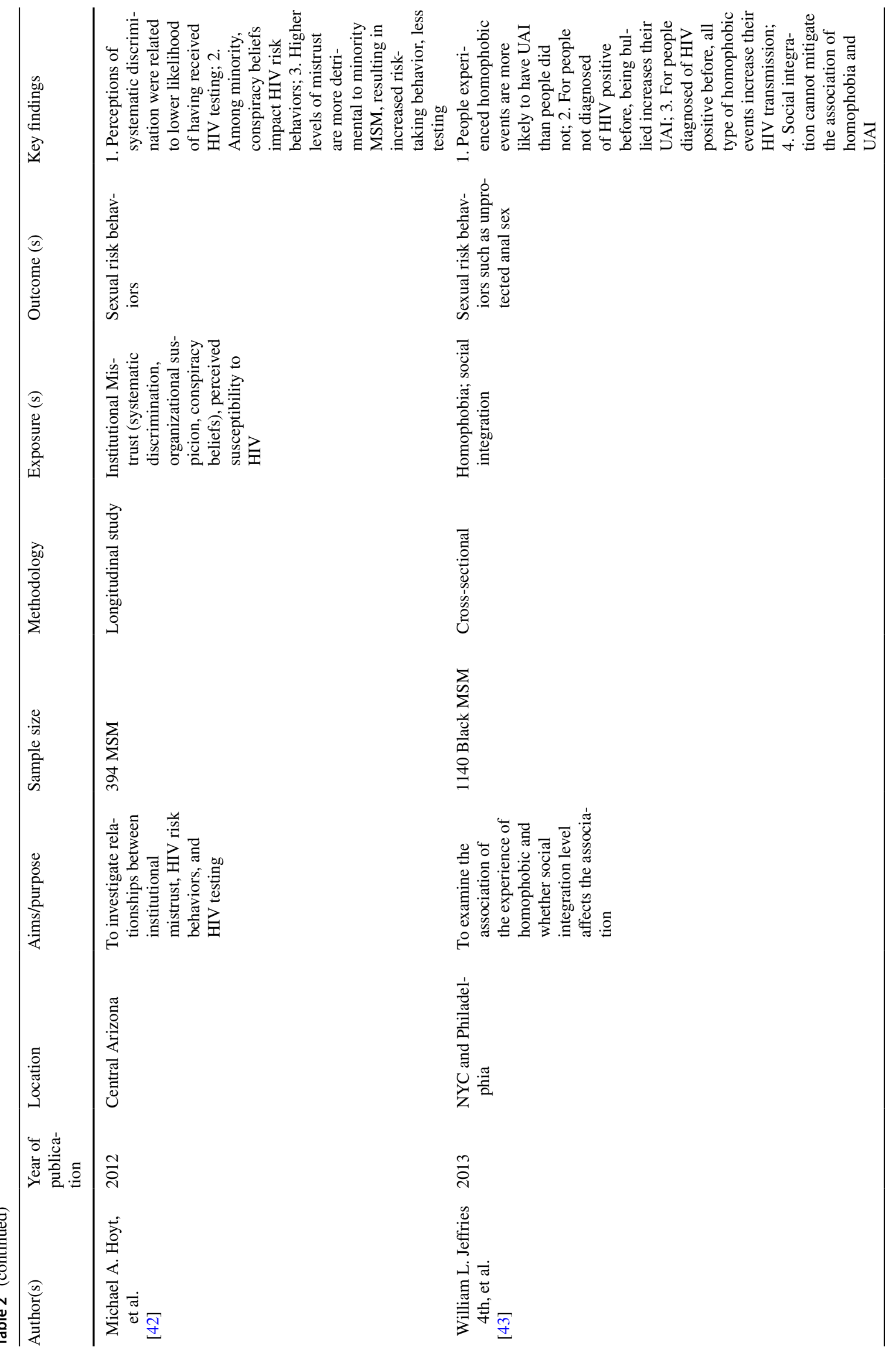




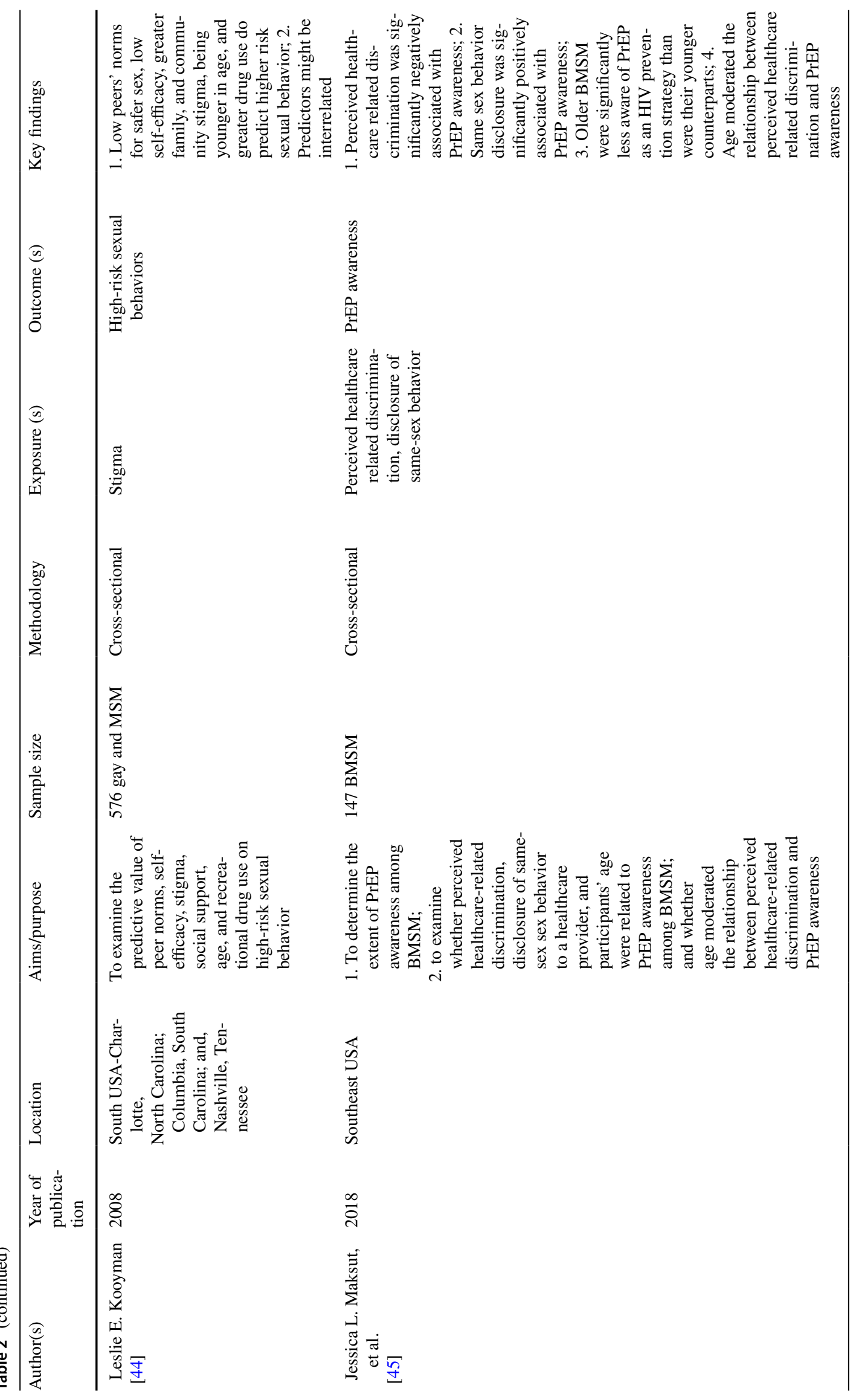




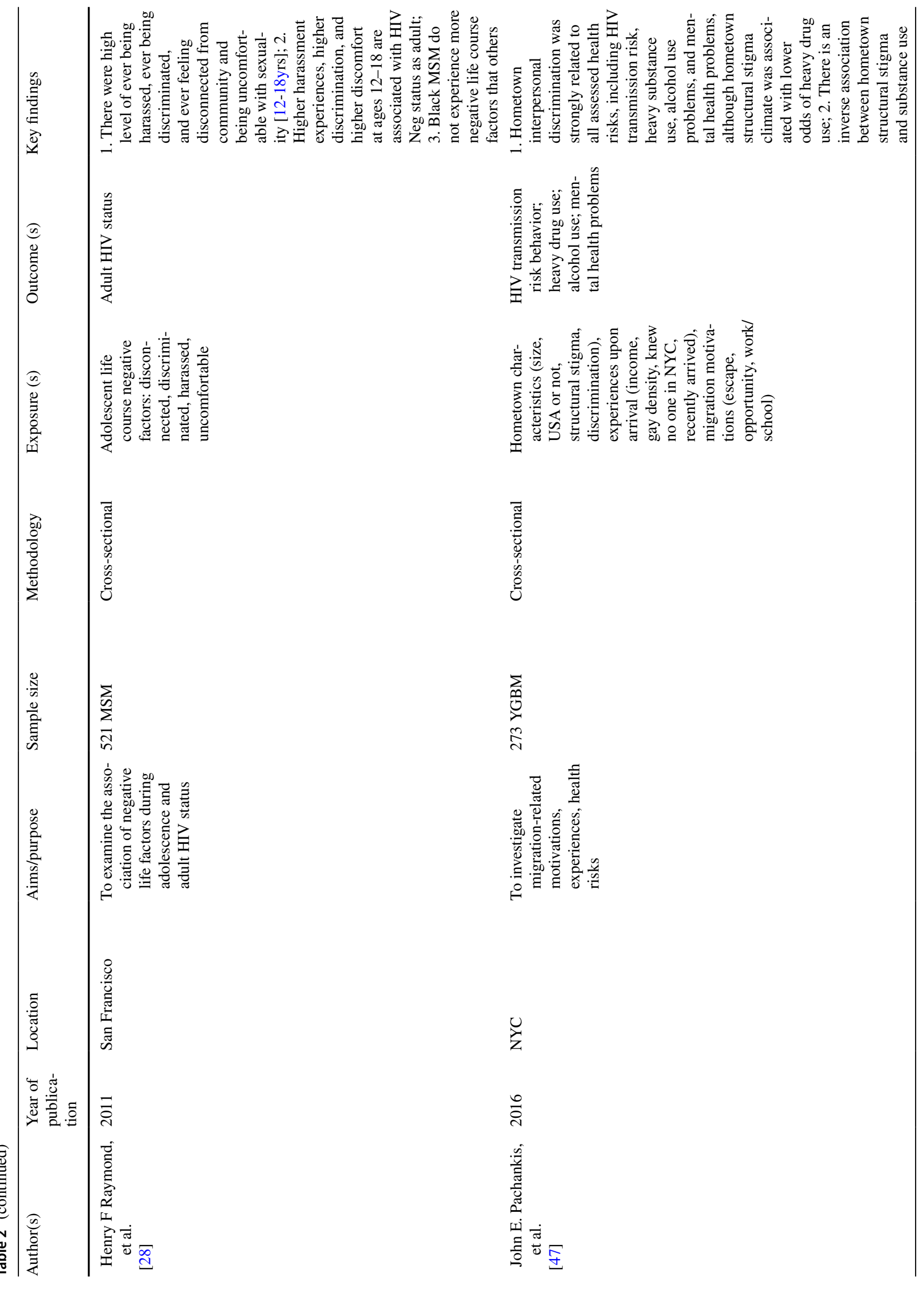




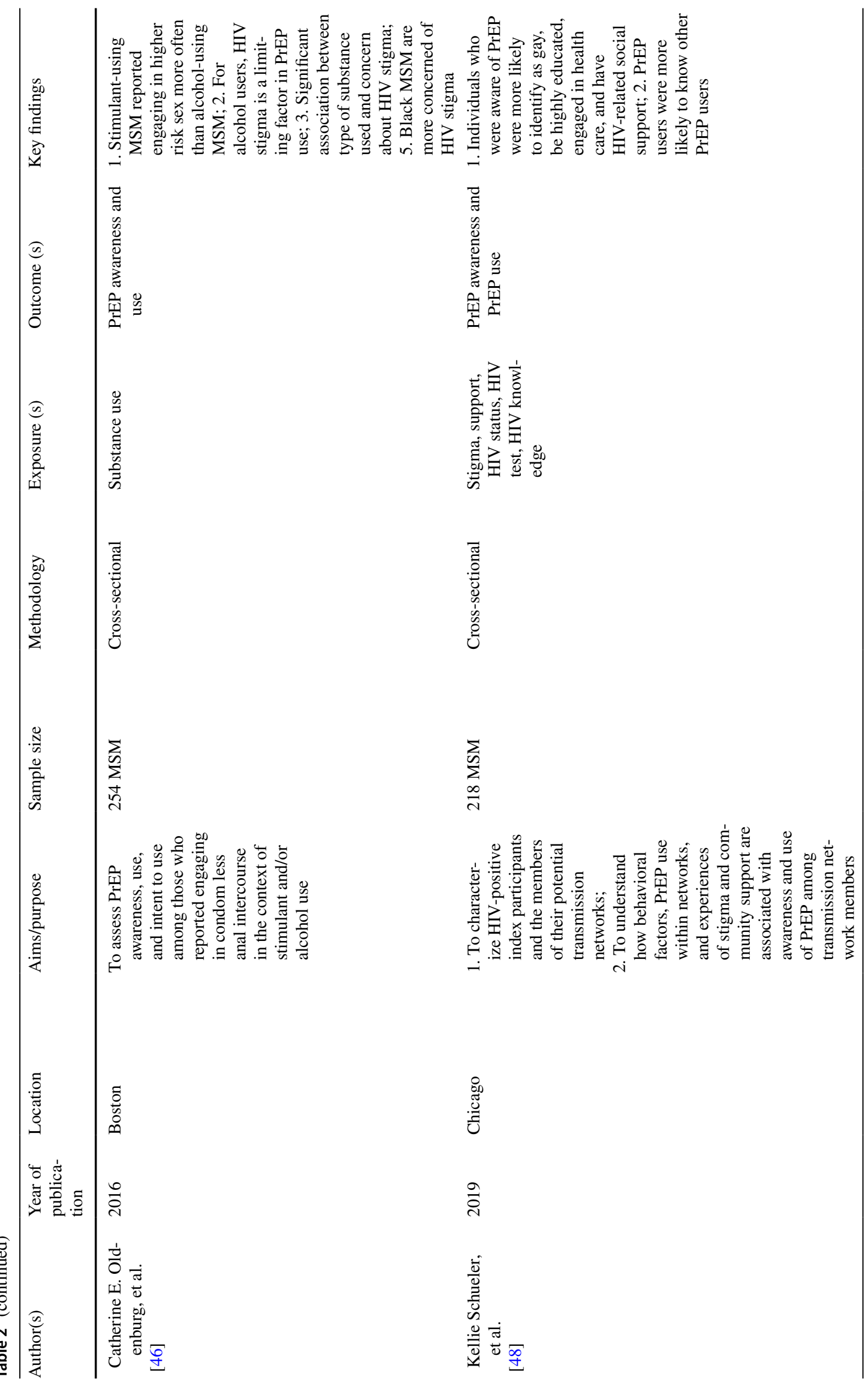




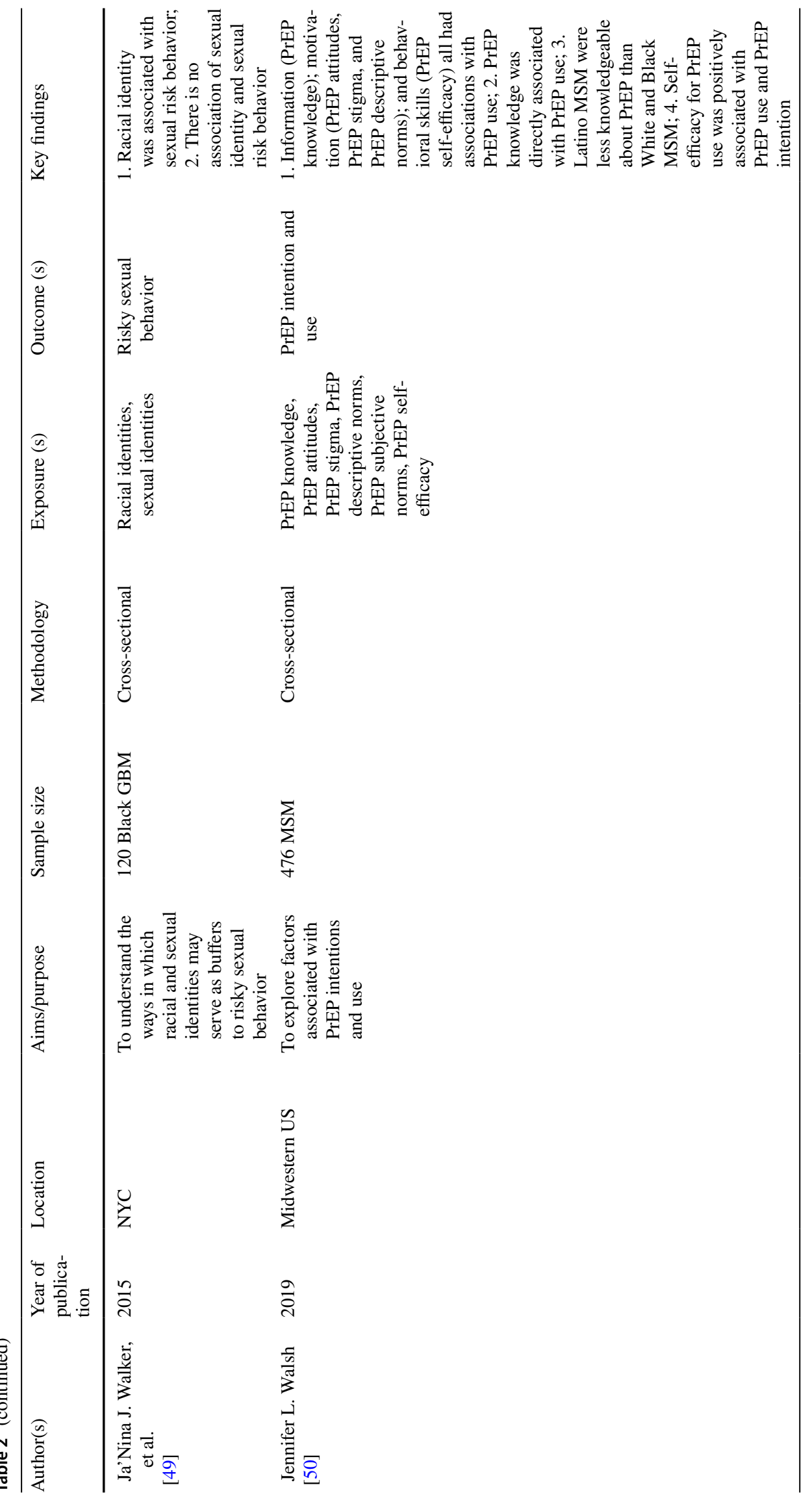




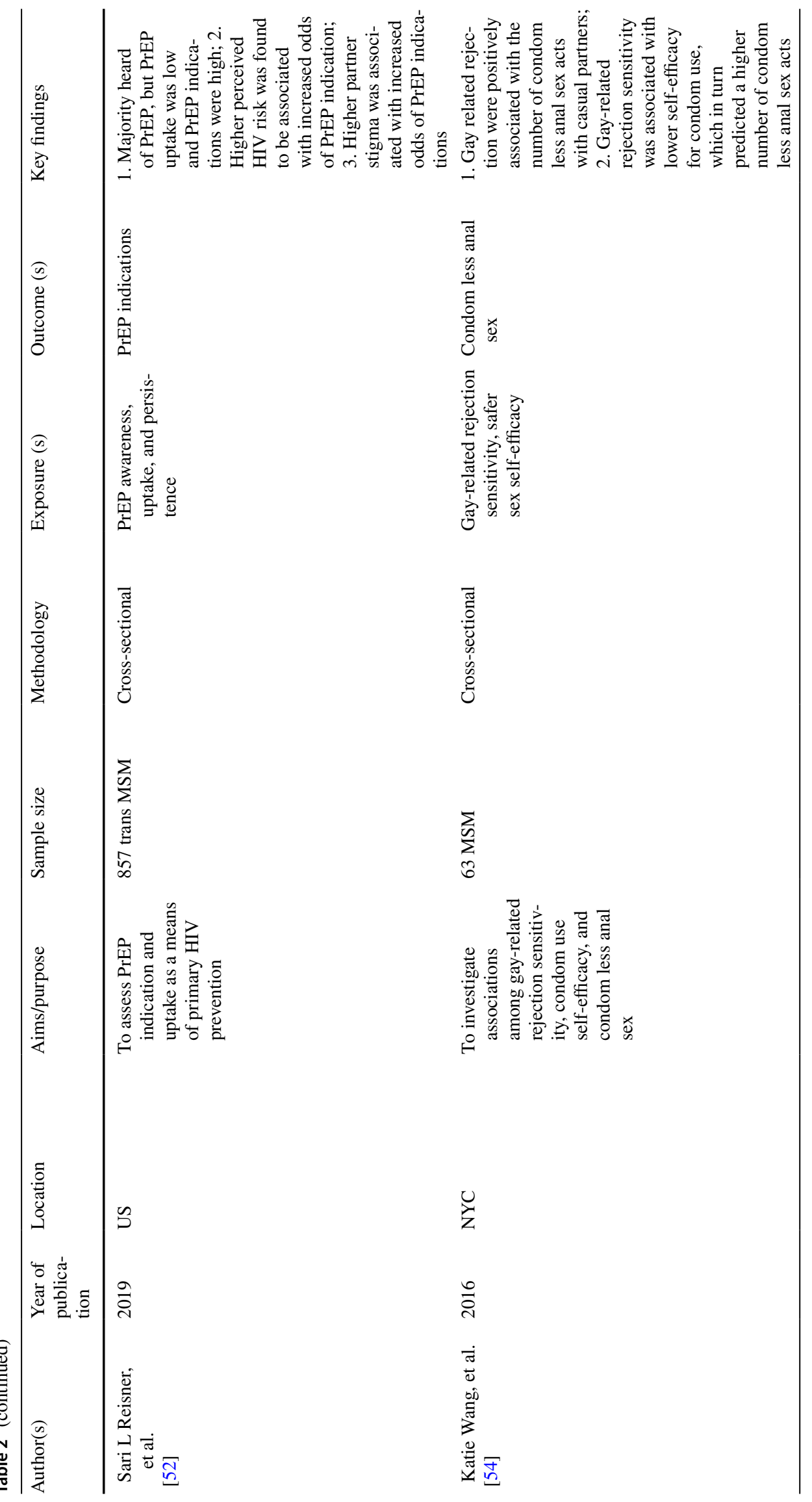




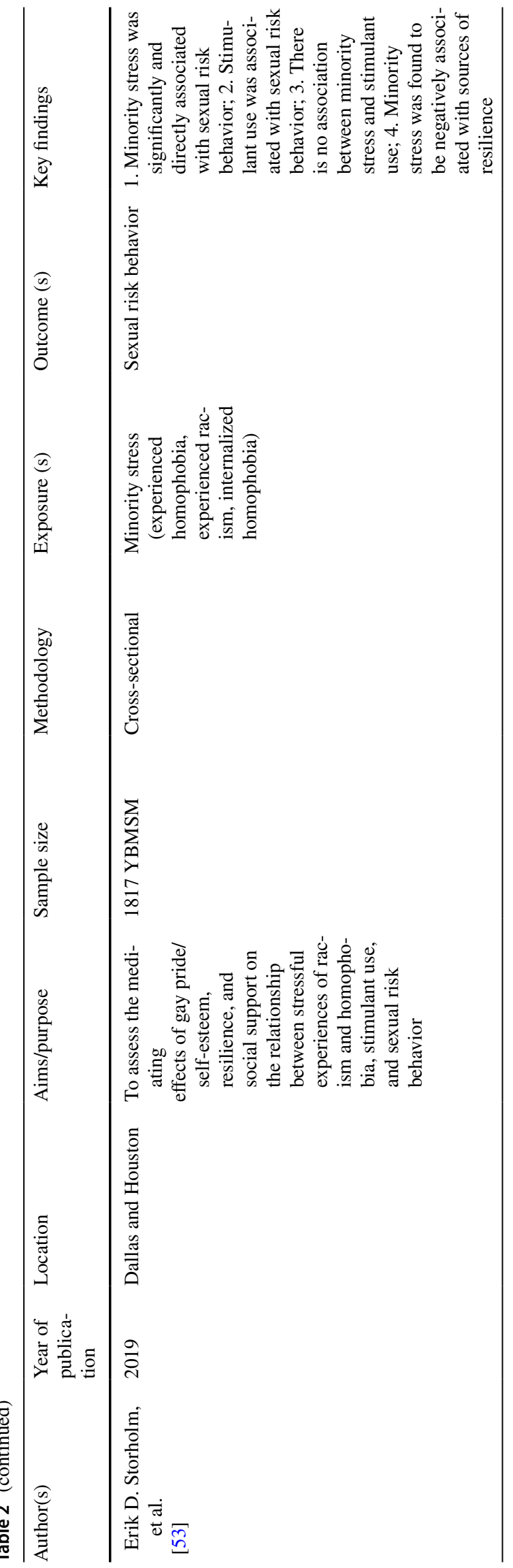




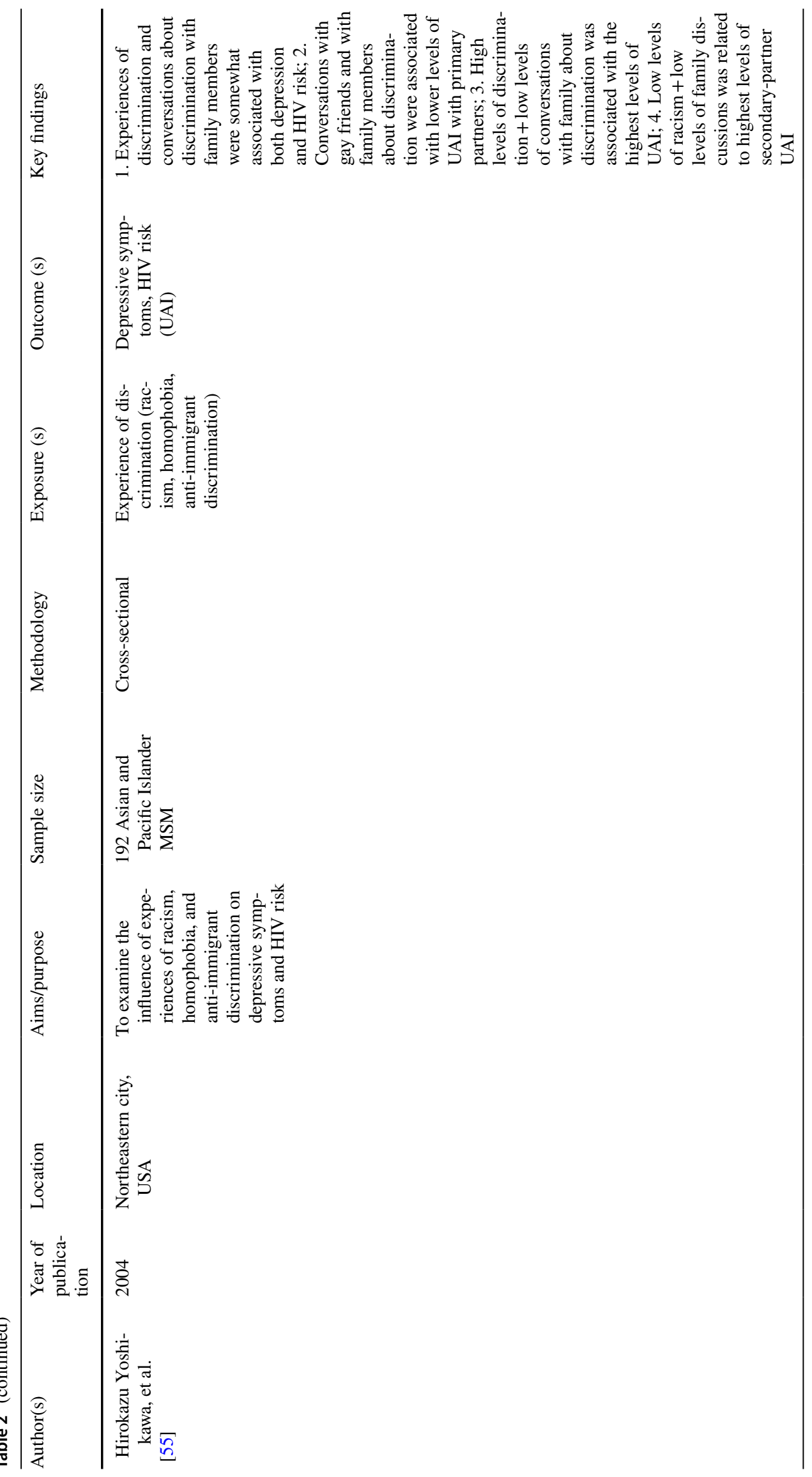




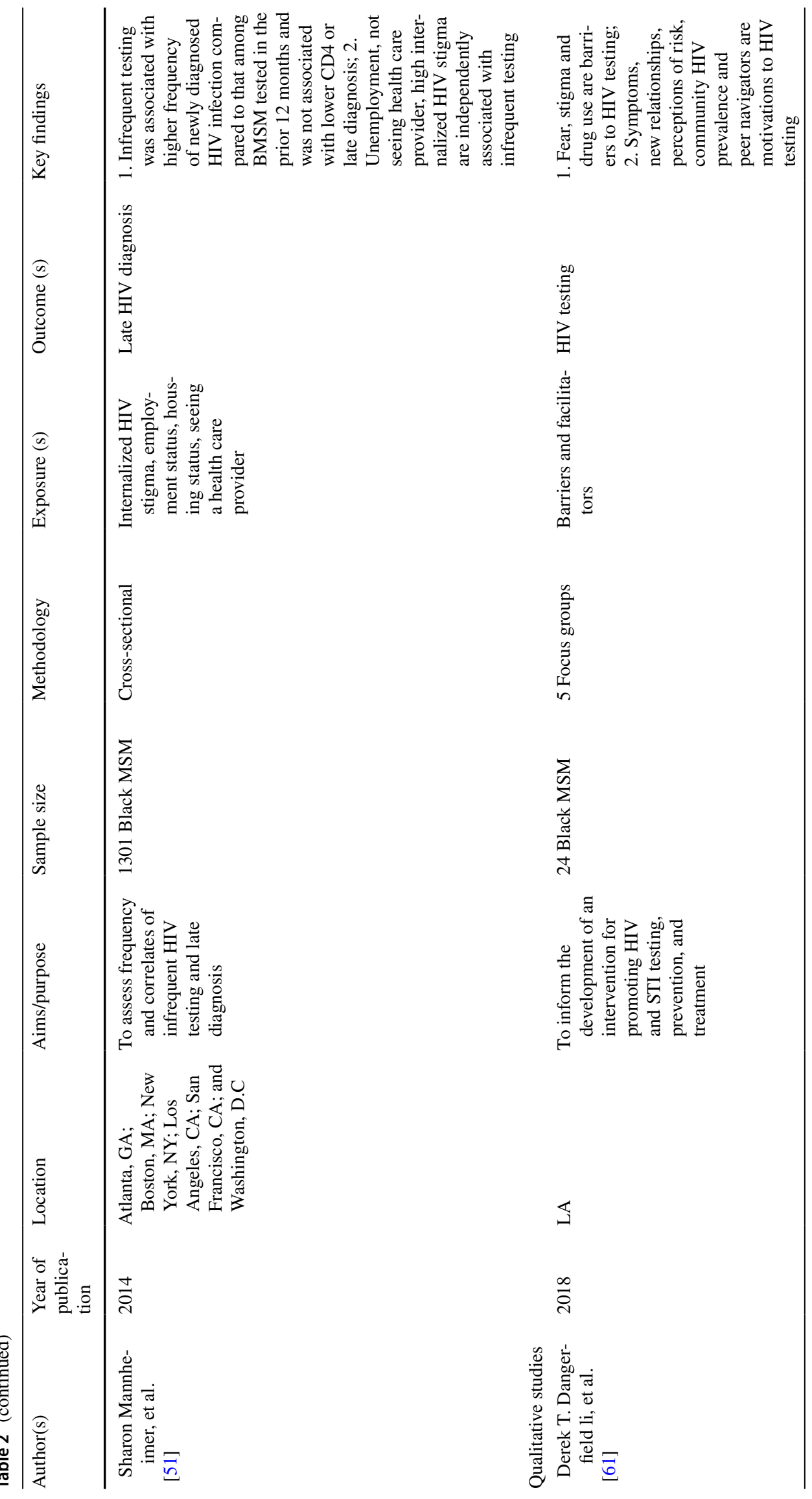




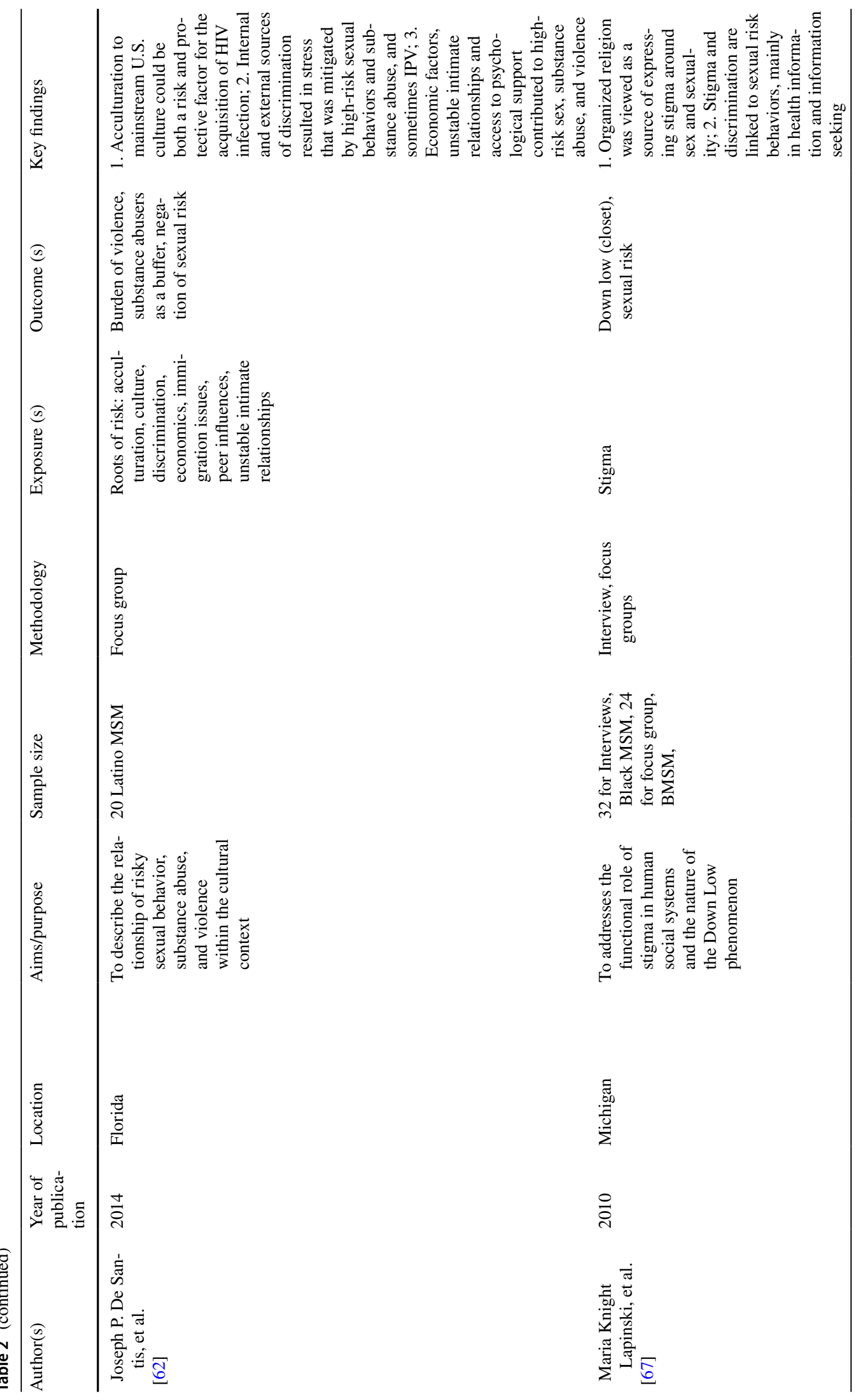




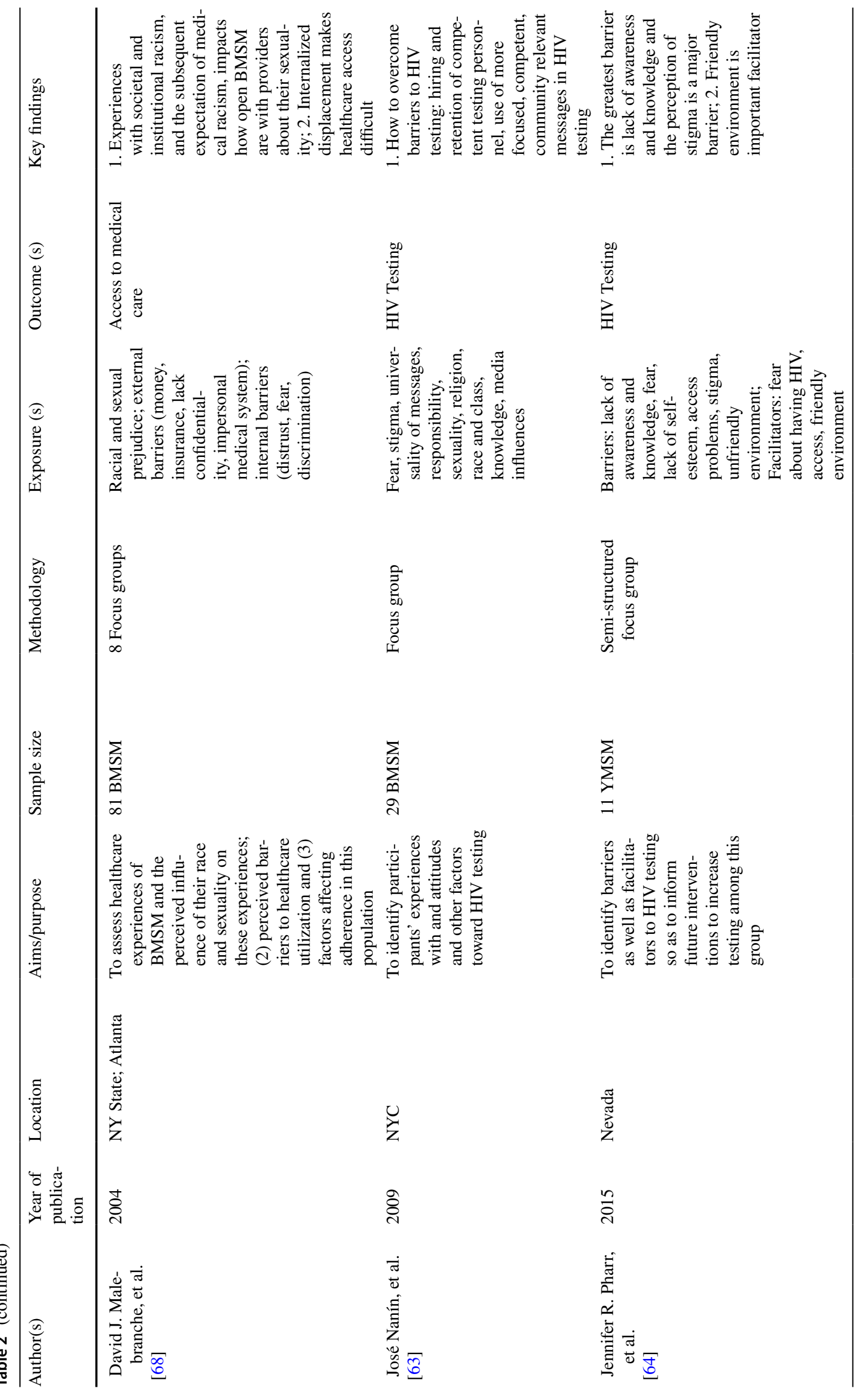




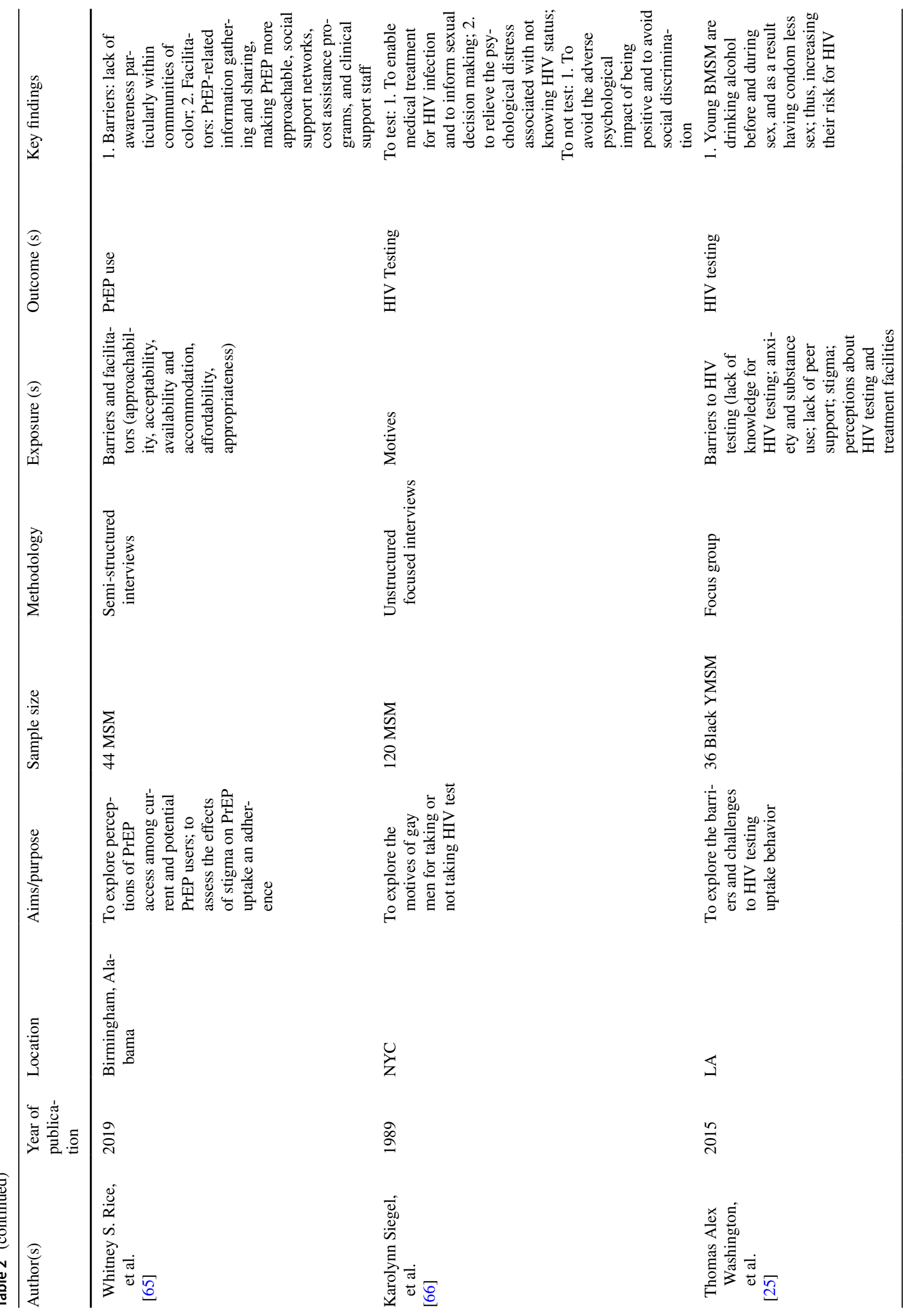




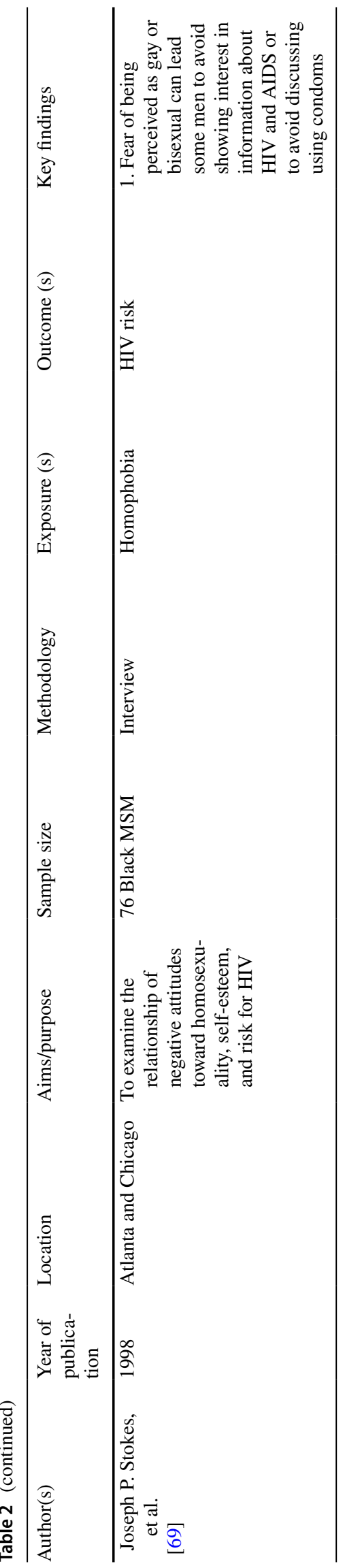

testing, and the psychological impact that the fear of a positive test result might also act as a barrier to HIV prevention measures [61, 66].

Among MSM with HIV, a total of eight studies addressed relationship between stigma and care continuum. Specifically, among older Black MSM in the South or elsewhere, medical care settings that are considered to be a safety net, were themselves a source of stigmatization [58-60]. The ability to manage their illness was impeded if individuals were structurally marginalized by the healthcare organizations. This was predominantly due to lower linkage to care, retention in care, adherence to antiretroviral therapy (ART), and inability to achieve viral suppression. Consequently, individuals usually weaken the care continuum by either missing the stages completely or by exiting the continuum altogether for a period of time. As a result, they revert back to an earlier stage in the HIV treatment cascade due to the fear of stigma and discrimination associated with HIV diagnosis. Since YMSM of color are disproportionately affected by HIV $[35,70]$, various domains of HIV stigma act differently in relation to care continuum outcomes, for example, internalized HIV stigma was negatively associated with viral load suppression [35] whereas perceived HIV stigma was a deterrent to engagement in care [70]. However, another form of HIV related stigma, disclosure of HIV status, was not found to be associated with either viral load suppression or medication adherence [35]. Depression was found to mediate the association between enacted and anticipated HIV related stigma and adherence to medications, but not between perceived HIV stigma and sexual risk behaviors [20, 31]. As compared to Hispanics, the persistence of discrimination due to race was higher specifically among Blacks, leading to an exacerbation of AIDS-related symptoms [30].

\section{Discussion}

The purpose of this review was to examine different types of stigma and how they affect HIV prevention, care, and treatment services among MSM in the United States. As evidenced by this review, HIV vulnerability generated through structural inequalities among MSM is fueled by social stigma and discrimination that influences their behaviors and health outcomes. Thus, the interplay between multiple stigmatized identities can severely intensify the negative detrimental health effects among MSM. Several important factors stood out during this review. First, since the advent of HAART is considered one of the historic achievements, we chose to examine this larger time frame within the context of stigma. While the treatment has definitely improved the prognosis for HIV positive individuals, we wanted to understand whether there were any studies concerning stigma and HIV risks or syndemic conditions in the pre-treatment era. 
However, we did not find any studies that had been conducted in this regard. Second, the other significant gap that were reported in the literature was the lack of research among YMSM of color. These individuals experience disparities across the HIV care continuum and it has further been demonstrated that stigma impacts the willingness to use PrEP among YMSM regardless of where they live in the US [72]. Perceptions about PrEP use were challenged and determined by societal stigmas such as racism, homophobia, healthcare access along with individual factors such as age and employment. Thus, the disparities in HIV incidence among men of color are further increased due to their inability to discuss PrEP with a healthcare provider and lack of health coverage $[73,74]$. As already established in the literature, knowledge about PrEP is directly related to its use and therefore the campaign by CDC about PrEP is very crucial, especially, within the non-White communities. However, while education raises awareness and improve knowledge, it is often not the primary factor in changing behavior. Structural interventions such as increasing access to PrEP and decreasing stigma associated with PrEP uptake/use is far more crucial by decreasing provider-patient stigma, increasing access to easy and free PrEP, and ensuring that those on PrEP are able to stay on PrEP. Therefore, to increase the PrEP care continuum among MSM, multilevel interventions, increased dialogue concerning sexuality and visibility with social groups and community groups are needed.

Third, Southern states have reported disproportionate number of new infections among MSM, however, few studies conducted in this region were focused on stigma. This is surprising, since it has already been established that transmission of HIV is mainly dependent on individual sexual networks and social conditions such as poverty, prejudice, and inequality. Studies have shown that within African American MSM communities, sexual networks are mostly closed and interconnected due to racism such that, if HIV is introduced, it is more likely to be transmitted to a large proportion of other African Americans than to outside groups [75-77]. Our review also revealed that none of these studies included MSM in rural areas, where stigma may be higher than urban areas [78]. In addition, the scant number of studies that have been carried out specifically among Hispanics may not be generalizable because many were conducted using qualitative research methodology. Furthermore, due to a lack of longitudinal studies, our ability to account for temporal ordering; that is, that stigma led to the inability to access components of HIV prevention or treatment services is limited. As most of these quantitative studies were cross-sectional in nature, any associations that have been observed, cannot be considered causal. A mixed-method approach should be employed among this population where participant's experiences would be grounded in quantitative findings.
Fourth, empirical findings from this study emphasize the need for future research and intervention studies to better understand and address intersectional stigma. Intersectional stigma continues to be a barrier to the uptake of HIV testing and evidence-based prevention interventions. The need to address intersectional stigma has been corroborated by the fact that these already marginalized groups due to one stigma are yet further stigmatized by membership in another stigmatized group based on their serostatus thus further exacerbating negative health outcomes. There is very limited research that has been conducted to understand and analyze intersectional stigma that may drive HIV vulnerability among MSM. Furthermore, interventions designed to address intersectional stigma in order to improve HIV prevention outcomes are notably absent from the literature. There is an urgent need to integrate an intersectionality lens by addressing the multi-level factors that frequently play a role in the experiences of marginalized populations. Science-based dissemination of measurement of intersectional stigma, along with HIV prevention and treatment strategies, would be crucial in mitigating this type of stigma. Future studies should focus more on the intricate co-existence and interactions between different types of stigma and concurrent health conditions.

Finally, the impact of syndemics among MSM on the increased risk for HIV infection have been clearly established as seen in the studies above. While prior work has established the deleterious impact on mental health, stigma not only increases their risk of infection but also has an additive impact on poor antiretroviral uptake, lower medication adherence and viral suppression [19, 79]. Thus, these synergistically acting syndemic factors should not be treated in isolation and instead they should be regularly screened for and treated as an essential step in HIV care continuum. Hence, applying a holistically integrated approach to HIV care among MSM is suggested.

There are several limitations to our scoping review. The scope of the review was restricted to only English peer reviewed based articles, thereby introducing a potential bias by not accounting for relevant studies that would have been published in other languages. We noted the individual study designs as described in the literature, however, as is typical for scoping reviews, we did not intend to assess the quality of the information analyzed. Thus, the conclusions of this review are based on the existence of studies rather than their quality. Due to the limited number of studies, our study was not able to measure the strength of association between one particular type of stigma and one type of HIV outcome. By conducting a scoping review, we intended to answer broader research questions. Our hope is that findings from our review will provide a blueprint for future research on this important topic such as conducing meta-analyses to answer more nuanced and specific research questions while 
the literature continues to grow. Furthermore, this review provides a comprehensive overview of the existing research on stigma and its associated health outcomes suggesting that research attention to stigma is a field with more attention among MSM in the United States.

Therefore, to address the health disparities among this highly stigmatized populations, an ideal combination of stigma reduction interventions along with TasP would be required. Moreover, interventions will have to be tailored to be culturally specific, suitable, and appropriate to address the critical gap in the care continuum in this population. Finally, existing laws, programs and policies should be evaluated, and evidence-based intervention and policy changes should be made.

\section{Conclusions}

Although significant progress has been made in the field of HIV/AIDS, the greatest public health challenge in the fight against the HIV epidemic may still be stigma and discrimination. It is essential to disentangle the stigma associated with risk of acquisition of HIV and prevention efforts. MSM often hold multiple intersecting identities, and the stigma and discrimination they face related to these identities, can impact their health outcomes. Stigmatizing beliefs can severely influence an individual's decision to seek care and act as a barrier to testing, numerous intervention programs, healthcare access, and treatment adherence. This can lead to severe public health ramifications. There is an urgent need to bridge the gap in programmatic knowledge regarding stigma and the vulnerable risk categories. The integration of different measures of stigma approaches along with psychological and social supports should be incorporated into the national HIV response.

Supplementary Information The online version contains supplementary material available at https://doi.org/10.1007/s10461-021-03262-4.

Acknowledgements The authors acknowledge the helpful guidance of Yingting Zhang, a research services librarian at the Robert Wood Johnson Library of the Health Sciences for her guidance during the implementation of the search.

Author contributions $\mathrm{CY}$ and RAB conceived the paper and developed the search strategy. RAB drafted the manuscript. RAB implemented the search strategy, led the title, abstract, full-text review and data abstraction processes of this article. PW contributed to the title, abstract, and full-text reviews and the data abstraction. All authors (RAB, PW, EJA, HR, CY) critically revised and approved the final version of manuscript.

\section{Declarations}

Conflict of interest The authors declare that they have no conflict of interest.

\section{References}

1. Crocker J, Major B. Social stigma and self-esteem: the self-protective properties of stigma. Psychol Rev. 1989;96(4):608-30.

2. Crocker J, Major B. The self-protective properties of stigma: evolution of a modern classic. Psychol Inq. 2003;14(3/4):232-7.

3. Van Brakel WH. Measuring health-related stigma: a literature review. Psychol Health Med. 2006;11(3):307-34.

4. Earnshaw VA, Smith LR, Chaudoir SR, Amico KR, Copenhaver MM. HIV stigma mechanisms and well-being among PLWH: a test of the HIV stigma framework. AIDS Behav. 2013;17(5):1785-95.

5. Logie C, Gadalla TM. Meta-analysis of health and demographic correlates of stigma towards people living with HIV. AIDS Care. 2009;21(6):742-53.

6. Phillips KD, Moneyham L, Tavakoli A. Development of an instrument to measure internalized stigma in those with HIV/AIDS. Issues Ment Health Nurs. 2011;32(6):359-66.

7. Crenshaw K. Demarginalizing the intersection of race and sex: a black feminist critique of antidiscrimination doctrine, feminist theory and antiracist politics. Univ Chic Leg Forum. 1989;140:139-67.

8. Bowleg L. When Black + Lesbian + Woman $\neq$ Black Lesbian Woman: the methodological challenges of qualitative and quantitative intersectionality research. Sex Roles. 2008;59(5):312-25.

9. Turan JM, Elafros MA, Logie CH, et al. Challenges and opportunities in examining and addressing intersectional stigma and health. BMC Med. 2019;17(1):7.

10. Mahendra VS, Gilborn L, Bharat S, et al. Understanding and measuring AIDS-related stigma in health care settings: a developing country perspective. SAHARA J. 2007;4(2):616-25.

11. Mahajan AP, Sayles JN, Patel VA, et al. Stigma in the HIV/AIDS epidemic: a review of the literature and recommendations for the way forward. AIDS. 2008;22(Suppl 2):S67-79.

12. Ha H, Ross MW, Risser JMH, Nguyen HTM. Measurement of stigma in men who have sex with men in Hanoi, Vietnam: assessment of a homosexuality-related stigma scale. J Sex Transm Dis. 2013;2013:174506.

13. CDC. Estimated HIV incidence and prevalence in the United States, 2014-2018. HIV Surveillance Supplemental Report 2020.25 (No. 1).

14. Dyer TP, Shoptaw S, Guadamuz TE, et al. Application of syndemic theory to black men who have sex with men in the Multicenter AIDS Cohort Study. J Urban Health. 2012;89(4):697-708.

15. Stall R, Mills TC, Williamson J, et al. Association of co-occurring psychosocial health problems and increased vulnerability to HIV/ AIDS among urban men who have sex with men. Am J Public Health. 2003;93(6):939-42.

16. Santos G-M, Do T, Beck J, et al. Syndemic conditions associated with increased HIV risk in a global sample of men who have sex with men. Sex Transm Infect. 2014;90(3):250-3.

17. Stall R, Friedman M, Catania J. Interacting epidemics and gay men's health: a theory of syndemic production among urban gay men. Unequal Opportunity: Health Disparities Affecting Gay and Bisexual Men in the United States; 2007. p. 251-74.

18. Singer M, Clair S. Syndemics and public health: reconceptualizing disease in bio-social context. Med Anthropol Q. 2003;17(4):423-41. 
19. Friedman MR, Stall R, Silvestre AJ, et al. Effects of syndemics on HIV viral load and medication adherence in the multicentre AIDS cohort study. AIDS. 2015;29(9):1087-96.

20. Hatzenbuehler ML, O'Cleirigh C, Mayer KH, Mimiaga MJ, Safren SA. Prospective associations between HIV-related stigma, transmission risk behaviors, and adverse mental health outcomes in men who have sex with men. Ann Behav Med. 2011;42(2):227-34

21. Pachankis JE. A transdiagnostic minority stress treatment approach for gay and bisexual men's syndemic health conditions. Arch Sex Behav. 2015;44(7):1843-60.

22. Egan JE, Frye V, Kurtz SP, et al. Migration, neighborhoods, and networks: approaches to understanding how urban environmental conditions affect syndemic adverse health outcomes among gay, bisexual and other men who have sex with men. AIDS Behav. 2011;15(Suppl 1):S35-50.

23. Granich RM, Gilks CF, Dye C, De Cock KM, Williams BG. Universal voluntary HIV testing with immediate antiretroviral therapy as a strategy for elimination of HIV transmission: a mathematical model. Lancet. 2009;373(9657):48-57.

24. Fallon S, Park J, Ogbue C, Flynn C, German D. Awareness and acceptability of pre-exposure HIV prophylaxis among men who have sex with men in Baltimore. AIDS Behav. 2017;21(5):1268-77.

25. Washington TA, D’Anna L, Meyer-Adams N, Malotte CK. From their voices: barriers to HIV testing among black men who have sex with men remain. Healthcare. 2015;3(4):933-47.

26. WHO. Programmatic update: antiretroviral treatment as prevention (TasP) of HIV and TB. 2012.

27. Courtenay-Quirk C, Wolitski RJ, Parsons JT, Gomez CA. Is HIV/AIDS stigma dividing the gay community? Perceptions of HIV-positive men who have sex with men. AIDS Educ Prev. 2006;18(1):56-67.

28. Raymond HF, Chen YH, Stall RD, McFarland W. Adolescent experiences of discrimination, harassment, connectedness to community and comfort with sexual orientation reported by adult men who have sex with men as a predictor of adult HIV status. AIDS Behav. 2011;15(3):550-6.

29. Arksey H, O'Malley L. Scoping studies: towards a methodological framework. Int J Soc Res Methodol. 2005;8(1):19-32.

30. Bogart LM, Landrine H, Galvan FH, Wagner GJ, Klein DJ. Perceived discrimination and physical health among HIV-positive Black and Latino men who have sex with men. AIDS Behav. 2013;17(4):1431-41.

31. Mitzel LD, Vanable PA, Brown JL, Bostwick RA, Sweeney SM, Carey MP. Depressive symptoms mediate the effect of HIV-related stigmatization on medication adherence among HIV-infected men who have sex with men. AIDS Behav. 2015;19(8):1454-9.

32. Rendina HJ, Gamarel KE, Pachankis JE, Ventuneac A, Grov C, Parsons JT. Extending the minority stress model to incorporate HIV-positive gay and bisexual men's experiences: a longitudinal examination of mental health and sexual risk behavior. Ann Behav Med. 2017;51(2):147-58.

33. Rendina HJ, Golub SA, Grov C, Parsons JT. Stigma and sexual compulsivity in a community-based sample of HIV-positive gay and bisexual men. AIDS Behav. 2012;16(3):741-50.

34. Wohl AR, Galvan FH, Myers HF, et al. Do social support, stress, disclosure and stigma influence retention in HIV care for Latino and African American men who have sex with men and women? AIDS Behav. 2011;15(6):1098-110.

35. Quinn K, Voisin DR, Bouris A, et al. Multiple dimensions of stigma and health related factors among young black men who have sex with men. AIDS Behav. 2017;21(1):207-16.

36. Anderson-Carpenter KD, Sauter HM, Luiggi-Hernández JG, Haight PE. Associations between perceived homophobia, community connectedness, and having a primary care provider among gay and bisexual men. Sex Res Social Policy. 2019;16(3):309-16.

37. Balaji AB, Bowles KE, Hess KL, Smith JC, Paz-Bailey G. Association between enacted stigma and HIV-related risk behavior among MSM, National HIV behavioral surveillance system, 2011. AIDS Behav. 2017;21(1):227-37.

38. Delgado AJ, Gordon D, Schnarrs P. The effect of discrimination and stress on sexual and behavioral health among sexual minority servicemen. J Gay Lesbian Ment Health. 2016;20(3):258-79.

39. Finneran C, Stephenson R. Intimate partner violence, minority stress, and sexual risk-taking among US men who have sex with men. J Homosex. 2014;61(2):288-306.

40. Frye V, Nandi V, Egan J, et al. Sexual orientation- and race-based discrimination and sexual HIV risk behavior among urban MSM. AIDS Behav. 2015;19(2):257-69.

41. Goldenberg T, Stephenson R, Bauermeister J. Community stigma, internalized homonegativity, enacted stigma, and HIV testing among young men who have sex with men. J Community Psychol. 2018;46(4):515-28.

42. Hoyt MA, Rubin LR, Nemeroff CJ, Lee J, Huebner DM, Proeschold-Bell RJ. HIV/AIDS-related institutional mistrust among multiethnic men who have sex with men: effects on HIV testing and risk behaviors. J Health Psychol. 2012;31(3):269-77.

43. Jeffries W, Marks G, Lauby J, Murrill CS, Millett GA. Homophobia is associated with sexual behavior that increases risk of acquiring and transmitting HIV infection among black men who have sex with men. AIDS Behav. 2013;17(4):1442-53.

44. Kooyman LE. Predictors of high-risk sexual behavior among gay men and men who have sex with men. J LGBT Issues Couns. 2008;2(4):285-307.

45. Maksut JL, Eaton LA, Siembida EJ, Fabius CD, Bradley AM. Health care discrimination, sex behavior disclosure, and awareness of pre-exposure prophylaxis among Black men who have sex with men. Stigma Health. 2018;3(4):330-7.

46. Oldenburg CE, Mitty JA, Biello KB, et al. Differences in attitudes about HIV pre-exposure prophylaxis use among stimulant versus alcohol using men who have sex with men. AIDS Behav. 2016;20(7):1451-60.

47. Pachankis JE, Eldahan AI, Golub SA. New to New York: ecological and psychological predictors of health among recently arrived young adult gay and bisexual urban migrants. Ann Behav Med. 2016;50(5):692-703.

48. Schueler K, Ferreira M, Nikolopoulos G, et al. Pre-exposure prophylaxis (PrEP) awareness and use within high HIV transmission networks. AIDS Behav. 2019;23(7):1893-903.

49. Walker JJ, Longmire-Avital B, Golub S. Racial and sexual identities as potential buffers to risky sexual behavior for black gay and bisexual emerging adult men. Health Psychol. 2015;34(8):841-6.

50. Walsh JL. Applying the information-motivation-behavioral skills model to understand PrEP intentions and use among men who have sex with men. AIDS Behav. 2019;23(7):1904-16.

51. Mannheimer SB, Wang L, Wilton L, et al. Infrequent HIV testing and late HIV diagnosis are common among a cohort of black men who have sex with men in 6 US cities. J Acquir Immune Defic Syndr. 2014;67(4):438-45.

52. Reisner SL, Moore CS, Asquith A, et al. High risk and low uptake of pre-exposure prophylaxis to prevent HIV acquisition in a national online sample of transgender men who have sex with men in the United States. J Int AIDS Soc. 2019;22(9):e25391.

53. Storholm ED, Huang W, Siconolfi DE, et al. Sources of resilience as mediators of the effect of minority stress on stimulant use and sexual risk behavior among young black men who have sex with men. AIDS Behav. 2019;23(12):3384-95.

54. Wang K, Pachankis JE. Gay-related rejection sensitivity as a risk factor for condomless sex. AIDS Behav. 2016;20(4):763-7. 
55. Yoshikawa H, Wilson PA, Chae DH, Cheng JF. Do family and friendship networks protect against the influence of discrimination on mental health and HIV risk among Asian and Pacific Islander gay men? AIDS Educ Prev. 2004;16(1):84-100.

56. Batchelder AW, Klevens M, Fitch C, McKetchnie SM, Mayer KH, O'Cleirigh C. Stigma, discrimination, and substance use among an urban sample men who have sex with men in Massachusetts. AIDS Care. 2020;32(3):370-8.

57. Bird JD, LaSala MC, Hidalgo MA, Kuhns LM, Garofalo R. "I had to go to the streets to get love": pathways from parental rejection to HIV risk among young gay and bisexual men. J Homosex. 2017;64(3):321-42.

58. Bird JD, Voisin DR. "You're an open target to be abused": a qualitative study of stigma and HIV self-disclosure among Black men who have sex with men. Am J Public Health. 2013;103(12):2193-9.

59. Haile R, Padilla MB, Parker EA. "Stuck in the quagmire of an HIV ghetto": the meaning of stigma in the lives of older black gay and bisexual men living with HIV in New York City. Cult Health Sex. 2011;13(4):429-42.

60. Jemmott JB, Zhang JW, Croom M, Icard LD, Rutledge SE, O'Leary A. Barriers and facilitators to engaging african american men who have sex with men in the HIV care continuum: a theory-based qualitative study. J Assoc Nurses AIDS Care. 2019;30(3):352-61.

61. Dangerfield Ii DT, Harawa NT, McWells C, Hilliard C, Bluthenthal RN. Exploring the preferences of a culturally congruent, peer-based HIV prevention intervention for black men who have sex with men. Sex Health. 2018;15(5):424-30.

62. De Santis JP, Gonzalez-Guarda R, Provencio-Vasquez E, Deleon DA. The tangled branches (Las Ramas Enredadas): sexual risk, substance abuse, and intimate partner violence among hispanic men who have sex with men. J Transcult Nurs. 2014;25(1):23-32.

63. Nanin J, Osubu T, Walker J, Powell B, Powell D, Parsons J. "HIV is still real": perceptions of HIV testing and HIV prevention among black men who have sex with men in New York City. Am J Mens Health. 2009;3(2):150-64.

64. Pharr JR, Lough NL, Ezeanolue EE. Barriers to HIV testing among young men who have sex with men (MSM): experiences from Clark county. Nevada Glob J Health Sci. 2015;8(7):9-17.

65. Rice WS, Stringer KL, Sohail M, et al. Accessing pre-exposure prophylaxis (PrEP): perceptions of current and potential PrEP users in Birmingham, Alabama. AIDS Behav. 2019;23(11):2966-79.

66. Siegel K, Levine MP, Brooks C, Kern R. The motives of gay men for taking or not taking the HIV antibody test. Soc Probl. 1989;36(4):368-83.

67. Lapinski MK, Braz ME, Maloney EK. The down low, social stigma, and risky sexual behaviors: insights from African-American men who have sex with men. J Homosex. 2010;57(5):610-33.
68. Malebranche DJ, Peterson JL, Fullilove RE, Stackhouse RW. Race and sexual identity: perceptions about medical culture and healthcare among black men who have sex with men. J Natl Med Assoc. 2004;96(1):97-107.

69. Stokes JP, Peterson JL. Homophobia, self-esteem, and risk for HIV among African American men who have sex with men. AIDS Educ Prev. 1998;10(3):278-92.

70. Remien RH, Bauman LJ, Mantell JE, et al. Barriers and facilitators to engagement of vulnerable populations in HIV primary care in New York City. J Acquir Immune Defic Syndr. 2015;69(Suppl 1):S16-24.

71. Barrington C, Davis DA, Villa-Torres L, Carcano J, HightowWeidman L. Intersectionalities and the HIV continuum of care among gay Latino men living with HIV in North Carolina. Ethn Health. 2019;2019:1-16.

72. Quinn K, Bowleg L, Dickson-Gomez J. "The fear of being Black plus the fear of being gay": the effects of intersectional stigma on PrEP use among young Black gay, bisexual, and other men who have sex with men. Soc Sci Med. 2019;232:86-93.

73. Finlayson T, Cha S, Xia M, et al. Changes in HIV preexposure prophylaxis awareness and use among men who have sex with men - 20 urban areas, 2014 and 2017. MMWR Morb Mortal Wkly Rep. 2019;68(27):597-603.

74. Mayer KH, Hosek S, Cohen S, et al. Antiretroviral pre-exposure prophylaxis implementation in the United States: a work in progress. J Int AIDS Soc. 2015;18(4 Suppl 3):19980.

75. Friedman SR, Cooper HL, Osborne AH. Structural and social contexts of HIV risk among African Americans. Am J Public Health. 2009;99(6):1002-8.

76. Raymond HF, McFarland W. Racial mixing and HIV risk among men who have sex with men. AIDS Behav. 2009;13(4):630-7.

77. Bingham TA, Harawa NT, Johnson DF, Secura GM, MacKellar DA, Valleroy LA. The effect of partner characteristics on HIV infection among African American men who have sex with men in the Young Men's Survey, Los Angeles, 1999-2000. AIDS Educ Prev. 2003;15(Suppl 1):39-52.

78. Preston DB, D'Augelli AR, Kassab CD, Starks MT. The relationship of stigma to the sexual risk behavior of rural men who have sex with men. AIDS Educ Prev. 2007;19(3):218-30.

79. Blashill AJ, Bedoya CA, Mayer KH, et al. Psychosocial syndemics are additively associated with worse ART adherence in HIVinfected individuals. AIDS Behav. 2015;19(6):981-6.

Publisher's Note Springer Nature remains neutral with regard to jurisdictional claims in published maps and institutional affiliations. 